\title{
An image-based four-source surface energy balance model to estimate crop evapotranspiration from solar reflectance/thermal emission data (SEB-4S)
}

\author{
Olivier Merlin ${ }^{*}$,, Jonas Chirouze ${ }^{\mathrm{a}}$, Albert Olioso ${ }^{\mathrm{b}}$, Lionel Jarlan ${ }^{\mathrm{a}}$, Ghani \\ Chehbouni $^{\mathrm{a}}$, Gilles Boulet ${ }^{\mathrm{a}}$ \\ ${ }^{a}$ Centre d'Etudes Spatiales de la Biosphère (CESBIO UMR5126), 31401 Toulouse, \\ France \\ ${ }^{b}$ INRA, EMMAH UMR1114, 84914 Avignon, France \\ UAPV, EMMAH UMR1114, 84000 Avignon, France
}

\section{Abstract}

A remote sensing-based surface energy balance model is developed to explicitly represent the energy fluxes of four surface components of agricultural fields including bare soil, unstressed green vegetation, non-transpiring green vegetation, and standing senescent vegetation. Such a four-source representation (SEB-4S) is achieved by a consistent physical interpretation of the edges and vertices of the polygon (named $T-f_{v g}$ polygon) obtained by plotting surface temperature $(T)$ as a function of fractional green vegetation $\left(f_{v g}\right)$ and the polygon (named $T-\alpha$ polygon) obtained by plotting $T$ as a function of surface albedo $(\alpha)$. To test the performance of SEB-4S, a $T-\alpha$ image-based model and a $T-f_{v g}$ image-based model are implemented as benchmarks. The three models are tested over a $16 \mathrm{~km}$ by $10 \mathrm{~km}$ irrigated area in northwestern Mexico during the 2007-2008 agricultural season. Input data are composed of ASTER (Advanced Spaceborne Thermal Emission and Reflec-

\footnotetext{
*telephone: +33 561556638; fax: +33 561558500; email: olivier.merlin@cesbio.cnes.fr
} 
tion Radiometer) thermal infrared, Formosat-2 shortwave, and station-based meteorological data. The fluxes simulated by SEB-4S, the $T-\alpha$ image-based model, and the $T-f_{v g}$ image-based model are compared on seven ASTER overpass dates with the in situ measurements collected at six locations within the study domain. The evapotranspiration simulated by SEB-4S is significantly more accurate and robust than that predicted by the models based on a single (either $T-f_{v g}$ or $T-\alpha$ ) polygon. The improvement provided with SEB-4S reaches about $100 \mathrm{~W} \mathrm{~m}^{-2}$ at low values and about $100 \mathrm{~W} \mathrm{~m}^{-2}$ at the seasonal peak of evapotranspiration as compared with both the $T-\alpha$ and $T-f_{v g}$ image-based models. SEB- $4 \mathrm{~S}$ can be operationally applied to irrigated agricultural areas using high-resolution solar/thermal remote sensing data, and has potential to further integrate microwave-derived soil moisture as additional constraint on surface soil energy and water fluxes.

Key words: Evapotranspiration, thermal, reflectance, temperature, albedo, partitioning, irrigation.

\section{Introduction}

2 Evapotranspiration (ET) plays a crucial role in predicting soil water availability (Oki and Kanae, 2006), in flood forecasting (Bouilloud et al., 2010), 4 in rainfall forecasting (Findell et al., 2011) and in projecting changes in the occurence of heatwaves (Seneviratne et al., 2006) and droughts (Sheffield and Wood,

6 2008). The partitioning of ET into its surface components including soil 7 evaporation, plant transpiration and canopy evaporation is important for 8 modeling vegetation water uptake, land-atmosphere interactions and climate 9 simulations. Large bare or partially covered soil surfaces especially occur in 
many cultivated areas. The soil evaporation term corresponds to the portion of ET that is unusable for crop productivity (Wallace, 2000) and its participation as a component of water balance may become dominant over bare or partially vegetated soils (Allen et al., 1998). Moreover, knowledge of ET partitioning would provide a powerful constraint on the physics of land surface models (Gutmann and Small, 2007). However, field measurements of both soil evaporation and plant transpiration are very sparse, and the current solar/thermal remote sensing techniques do not fully address the partitioning issue. This is notably due to the difficulty in separating the soil and vegetation components at the different phenological stages of crops from reflectance and thermal infrared data alone (Moran et al., 1994; Merlin et al., 2010, 2012a).

A number of models have been developed to estimate ET from thermal remote sensing data (Courault et al., 2005; Gowda et al., 2008). Actual ET has been estimated by weighting the potential ET using reflectancederived fractional photosynthetically-active (green) vegetation cover $\left(f_{v g}\right)$ (Allen et al., 1998; Cleugh et al., 2007). $f_{v g}$-based modeling approaches are useful to provide ET estimates over integrated time periods e.g. the agricultural season. The point is that $f_{v g}$ is not sensitive to vegetation water stress until there is actual reduction in biomass or changes in canopy geometry (Gonzalez-Dugo et al., 2009). As a result $f_{v g}$-based ET methods are not adapted to operational irrigation management when the objective is to detect the onset of water stress. Instead, canopy temperature can detect crop water deficit (Idso et al., 1981; Jackson et al., 1981). Operational ET models have hence been developed to monitor ET and soil moisture status from 
remotely sensed surface temperature $(T)$ (Boulet et al., 2007; Hain et al., 2009; Anderson et al., 2012). Note that T-based ET models may also use $f_{v g}$ to partition soil and vegetation components (Norman et al., 1995), and surface albedo $(\alpha)$ as additional constraint on net radiation (Bastiaanssen et al., 1998). Among the T-based ET methods reviewed in Kalma et al. (2008) and Kustas and Anderson (2009), one can distinguish the single-source models (Bastiaanssen et al., 1998; Su, 2002, e.g.) and the two-source models (Moran et al., 1994; Norman et al., 1995, e.g.), which implicitly and explicitly represent soil evaporation and plant transpiration, respectively. Although both model representations may perform similarly in terms of ET estimates given they are correctly calibrated (Timmermans et al., 2007), the two-source models are of particular interest for ET partitioning.

Among T-based two-source ET models, one can distinguish the residualbased models (Norman et al., 1995; Anderson et al., 2007; Cammalleri et al., 2012, e.g.), which estimate ET as the residual term of an aerodynamic resistance surface energy balance equation, and the image-based models (Moran et al., 1994; Roerink et al., 2000; Long and Singh, 2012, e.g.), which estimate ET as a fraction (named surface evaporative efficiency or EE) of potential ET (Moran et al., 1994), or as a fraction (named surface evaporative fraction or EF) of available energy (Roerink et al., 2000; Long and Singh, 2012). In image-based models, EF (or EE) is estimated as the ratio of the maximum to actual surface temperature difference to the maximum to minimum surface temperature difference. In Moran et al. (1994) and Long and Singh (2012), maximum and minimum temperatures are estimated over the dry and wet surface edges of a polygon drawn in the $T-f_{v g}$ space, 
respectively. In Roerink et al. (2000), maximum and minimum temperatures are estimated over the dry and wet surface lines drawn in the $T-\alpha$ space, respectively. As clearly stated by Tang et al. (2010), the advantages of image-based models over the residual-based models are 1) absolute high accuracy in remotely sensed $T$ retrieval and atmospheric correction are not indispensable, 2) complex parameterization of aerodynamic resistance and uncertainty originating from replacement of aerodynamic temperature by remotely sensed $T$ is bypassed 3) no ground-based near surface measurements are needed other than remotely sensed $T, f_{v g}$ and $\left.\alpha, 4\right)$ a direct calculation of EF (or EE) can be obtained without resort to surface energy balance, and 5) estimations of EF (or EE) and available energy (or potential ET) are independent from each other by this method. Therefore, the overall errors in ET can be traced back to EF (EE) and available energy (potential ET) separately. Limitations of image-based models mainly lie in the determination of the maximum and minimum surface temperatures. Specifically, the dry and wet edges can be placed accurately in the $T-f_{v g}$ or $T-\alpha$ space if 1 ) the full range of surface (soil moisture and vegetation cover) conditions is met within the study domain at the sensor resolution, 2) meteorological conditions are uniform in the study domain (Long et al., 2011, 2012), 3) the study domain is flat. In the case where all three conditions are not satisfied, alternative algorithms can be implemented to filter outliers in the $T-f_{g v}$ space (Tang et al., 2010), to estimate the maximum vegetation temperature from the $T-\alpha$ space (Merlin et al., 2010, 2012b), to estimate extreme temperatures using a formulation of aerodynamic resistance (Moran et al., 1994; Long et al., 2012), or to correct remotely sensed $T$ for topographic effects 
(Merlin et al., 2013).

Moran et al. (1994) proposed the $T-f_{v g}$ image-based water deficit index (WDI) to estimate a most probable range of crop water stress over partiallyvegetated pixels. The different steps of the WDI method are: 1) the temperatures of the four vertices of the $T-f_{v g}$ polygon are estimated using an energy balance model, 2) the minimum and maximum probable vegetation temperatures are estimated from the measured composite $T$, together with the maximum and minimum simulated soil temperatures, and 3) the minimum and maximum probable water stress indices are computed by normalizing the minimum and maximum probable vegetation temperatures from the vegetation temperature extremes simulated by the energy balance model. Note that the WDI approach does not allow estimating a single crop water stress index value because the canopy temperature retrieval problem is illposed using solely $T$ and $f_{v g}$. As mentioned in Moran et al. (1994) and Merlin et al. (2012a), knowledge of soil temperature would remove the underdetermination of the $T-f_{v g}$ polygon approach. A second limitation of the $T-f_{v g}$ polygon approach is that $f_{v g}$ does not allow distinguishing between soil and senescent vegetation, whereas the energy fluxes over bare soil and full-cover senescent vegetation may significantly differ. Separating vegetated areas according to the fraction of green versus senescent vegetation could be done by introducing additional information based on $\alpha$ (Merlin et al., 2010) or a vegetation index such as the Cellulose Absorption Index (Nagler et al., 2003; Krapez and Olioso, 2011). Note that optical data provide information on the surface skin only, which inherently prevents from separating green and senescent vegetation in the vertical dimension. 
Roerink et al. (2000) proposed the Simplified Surface Energy Balance Index (S-SEBI) to estimate ET from the $T-\alpha$ space. S-SEBI determines the wet and dry lines by interpreting the observed correlations between $T$ and $\alpha$ (Menenti et al., 1989). The wet line is defined as the lower limit of the $T-\alpha$ space. It generally has a positive slope as a result of an evaporation control on $T$. The dry line is defined as the upper limit of the $T-\alpha$ space. It generally has a negative slope as a result of a radiation control on $T$ (Roerink et al., 2000). One main advantage of the $T-\alpha$ space over the $T-f_{v g}$ space is that $\alpha$ is sensitive to the total vegetation cover including green and senescent vegetation, whereas $f_{v g}$ is sensitive to the green vegetation only (Merlin et al., 2010). One drawback is that unstressed green vegetation, non-transpiring vegetation and senescent vegetation are not easily separable in the $T-\alpha$ space, which makes identifying green crop water stress more difficult than using the $T-f_{v g}$ space. Moreover the slope of both wet and dry lines may be difficult to determine when the full physical range of $\alpha(\sim 0.1-0.4)$ is not covered within the study domain.

Although $T-f_{v g}$ and $T-\alpha$ image-based models have been applied separately (Choi et al., 2009), or intercompared (Galleguillos et al., 2011), there is no model that combines the strength of each polygon notably in terms of ET partitioning. The objective of this study is thus to develop an imagebased surface energy balance model (SEB-4S) that builds on advantages of both $T-f_{v g}$ and $T-\alpha$ spaces by 1) adequately constraining four surface components of agricultural fields including bare soil, unstressed green vegetation, non-transpiring green vegetation and standing senescent vegetation, 2) partitioning ET into soil evaporation and unstressed green vegetation tran- 
spiration, and 3) developing an automated algorithm for estimating temperature endmembers from joint $T-f_{v g}$ and $T-\alpha$ spaces. The modeling approach is tested over a $16 \mathrm{~km}$ by $10 \mathrm{~km}$ irrigated area in northwestern Mexico using ASTER (Advanced Spaceborne Thermal Emission and Reflection Radiometer) and Formosat-2 data collected on seven dates during the 2007-2008 agricultural season. Experimental data are described in Section 2. SEB- $4 \mathrm{~S}$ is described in Section 3, and two common $\left(T-f_{v g}\right.$ and $\left.T-\alpha\right)$ image-based models are reminded in Section 4. In Section 5, the surface fluxes simulated by SEB-4S, the $T-f_{v g}$ image-based model and the $T-\alpha$ image-based model are compared with in situ measurements at six locations.

\section{Data collection and pre-processing}

The Yaqui experiment was conducted from December 2007 to May 2008 over an irrigated area $\left(27.25^{\circ} \mathrm{N}, 109.88^{\circ} \mathrm{W}\right)$ in the Yaqui valley (Sonora State) in northwestern Mexico. The campaign focused on a $4 \mathrm{~km}$ by $4 \mathrm{~km}$ area including $50 \%$ of wheat, the other $50 \%$ being composed of beans, broccoli, chickpea, chili pepper, corn, orange, potatoes, safflower and sorghum. The objective of the experiment was to characterize the spatial variability of surface fluxes from the field (hectometric) to kilometric scale. More details about the Yaqui experiment can be found in Merlin et al. (2010), Fieuzal et al. (2011) and Chirouze et al. (2013). In this paper, the study area is defined as a $16 \mathrm{~km}$ by $10 \mathrm{~km}$ area containing the $4 \mathrm{~km}$ by $4 \mathrm{~km}$ Yaqui experimental area and included in all satellite images. During the 2007-2008 agricultural season, 7 cloud-free ASTER images were collected over the Yaqui area at around 11:00 am local solar time on December 30, February 23, March 10, 
April 11, April 27, May 6 and May 13 and 26 cloud-free Formosat-2 images were obtained from December 27, 2007 to May 13, 2008.

\subsection{Flux stations}

Seven micro-meteorological stations equipped with eddy covariance flux measurement system were installed in different fields. For each of the seven sites, the net radiation was acquired with CNR1 or Q7.1 (REBS) radiometers depending on the stations (see Table 1). The soil heat flux was estimated with HUKSEFLUX HFP-01 plates buried at $0.05 \mathrm{~m}$ at the top and bottom of the furrow (when applicable). Those data were acquired at a frequency of $10 \mathrm{~s}$ and then averaged and recorded each $30 \mathrm{~min}$. Latent and sensible heat fluxes were measured with KH20 fast response hygrometers (Campbell) and Campbell CSAT3 or RM Young 81000 3-D Sonic Anemometer at a frequency of $10 \mathrm{~Hz}$ and converted to $30 \mathrm{~min}$ average, respectively. Meteorological data including air temperature, solar radiation, relative humidity and wind speed were monitored throughout the agricultural season at a semi-hourly time step from December 27, 2007 until May 17, 2008. Details about the automated data acquisition and flux data quality can be found in Chirouze et al. (2013). In this paper, the six stations listed in Table 1 with at least four (among a total of seven) ASTER overpass dates of data including the four energy fluxes $(R n, G, L E, H)$ are used in the comparison analysis.

\subsection{ASTER thermal infrared data}

ASTER was launched in 1999 on a sun-synchronous platform (NASA's Terra satellite) with 11:00 am descending Equator crossing and a 16-day revisit cycle. The ASTER thermal sensor provides scenes of approximately 
$60 \mathrm{~km}$ by $60 \mathrm{~km}$. Data are collected on request over specified areas. There are five thermal bands centered at 8.30, 8.65, 9.05, 10.60 and $11.63 \mu \mathrm{m}$ with a $90 \mathrm{~m}$ resolution. ASTER official products were downloaded from the Earth Observing System Data Gateway and extracted over the $16 \mathrm{~km}$ by $10 \mathrm{~km}$ study area.

\subsubsection{Surface temperature}

The $90 \mathrm{~m}$ resolution surface skin temperature $(T)$ retrieved by the "temperature and emissivity separation" algorithm (Gillespie et al., 1998; Schmugge et al., 1998) was used. The absolute registration of temperature data was performed using a background $8 \mathrm{~m}$ resolution Formosat-2 image (Merlin et al., 2010).

\subsubsection{Broad-band surface emissivity}

The 90 m resolution ASTER channel emissivity retrieved by the "temperature and emissivity separation" algorithm was used. The absolute registration of emissivity data was set to that of temperature data on the same dates. The broad-band surface emissivity $(\epsilon)$ was expressed as a linear combination of ASTER channel emissivities using the coefficients in Ogawa and Schmugge (2004).

\subsection{Formosat-2 red and near-infrared data}

Formosat-2 is an Earth observation satellite launched in 2004 by the National Space Organization of Taiwan. It provides high $(8 \mathrm{~m})$ resolution images of a particular area every day (9:30 am equator-crossing time) for four bands (blue, green, red and near-infrared) and with the same view angle (Chern et al., 2008). In this paper, the Formosat-2 data collected on the nearest date from each of the seven ASTER overpass dates were used to 
estimate $f_{v g}$ and $\alpha$ from the red and near-infrared reflectances aggregated at ASTER thermal sensor resolution. The reason why Formosat-derived instead of ASTER-derived $\alpha$ was used is mainly because the ASTER shortwave infrared data were unusable on four out of the seven ASTER overpass dates (Chirouze et al., 2013).

\subsubsection{Fractional green vegetation cover}

Fractional green (photosynthetically active) vegetation cover $\left(f_{v g}\right)$ is estimated using the expression of Gutman and Ignatov (1998):

$$
f_{v g}=\frac{\mathrm{NDVI}-\mathrm{NDVI}_{\mathbf{s}}}{\mathrm{NDVI}_{\mathrm{vg}}-\mathrm{NDVI}_{\mathbf{s}}}
$$

with $\mathbf{N D V I}_{\mathbf{v g}}$ (for clarity all the variables defined at the $16 \mathrm{~km}$ by $10 \mathrm{~km}$ scale are written in bold) corresponding to fully-covering green vegetation and $\mathbf{N D V I}_{\mathbf{s}}$ to bare soil or to bare soil partially covered by senescent (nonphotosynthetically active) vegetation. In the paper, $\mathbf{N D V I}_{\mathbf{v g}}$ and $\mathbf{N D V I}_{\mathbf{s}}$ are set to the maximum (0.93) and minimum (0.18) value of the NDVI (Normalized Difference Vegetation Index) observed during the agricultural season within the study domain. NDVI is computed as the ratio of the difference between re-sampled Formosat-2 near-infrared and red reflectances to their sum.

\subsubsection{Surface albedo}

Surface albedo $(\alpha)$ is estimated as a weighted sum of re-sampled Formosat2 red and near-infrared reflectances with the coefficients given by Weiss et al. (1999) and validated in Bsaibes et al. (2009), and in Chirouze et al. (2013) over the study area. 


\section{SEB-4S model}

SEB-4S is based on the classical surface energy balance equation applied to four surface components: bare soil, unstressed green vegetation, non-transpiring green vegetation and senescent vegetation. ET is computed as the sum of the four component latent heat fluxes. A key step in the modeling approach is therefore to estimate the component fractions. While subsections 3.1 and 3.2 set the physical basis of SEB-4S, the following subsections 3.3-7 translate the physical interpretation of both $T-\alpha$ and $T-f_{v g}$ spaces into geometrical problems for solving the four component fractions. Along this section, the reader may refer to the definition of component fractions in Table 2, and to the schematic chart presented in Figure 1

\subsection{Surface energy balance}

The surface energy balance can be written as:

$$
R n-G=H+L E
$$

with $R n\left(\mathrm{Wm}^{-2}\right)$ being the surface net radiation, $G\left(\mathrm{Wm}^{-2}\right)$ the ground heat flux, $H\left(\mathrm{Wm}^{-2}\right)$ the surface sensible heat flux and $L E\left(\mathrm{Wm}^{-2}\right)$ the surface latent heat flux. In SEB-4S, the surface net radiation is decomposed into four components:

$$
R n=R n_{s}+R n_{v g u}+R n_{v g n}+R n_{v s s}
$$

with $R n_{s}\left(\mathrm{Wm}^{-2}\right)$ being the soil net radiation, $R n_{v g u}\left(\mathrm{Wm}^{-2}\right)$ the net radiation of unstressed green vegetation, $R n_{v g n}\left(\mathrm{Wm}^{-2}\right)$ the net radiation 
of non-transpiring green vegetation, and $R n_{v s s}\left(\mathrm{Wm}^{-2}\right)$ the net radiation of standing senescent vegetation.

Component net radiations are estimated as a fraction of surface net radiation:

$$
R n_{i}=f_{i} R n
$$

with $f_{i}(-)$ being the fraction of $i$ component, with $i=s, v g u, v g n$ and vss.

The decomposition of surface sensible heat flux into four components gives:

$$
H=H_{s}+H_{v g u}+H_{v g n}+H_{v s s}
$$

with $H_{s}\left(\mathrm{Wm}^{-2}\right)$ being the soil sensible heat flux, $H_{v g u}\left(\mathrm{Wm}^{-2}\right)$ the sensible heat flux over unstressed green vegetation, $H_{v g n}\left(\mathrm{Wm}^{-2}\right)$ the sensible heat flux over non-transpiring green vegetation, and $H_{v s s}\left(\mathrm{Wm}^{-2}\right)$ the sensible heat flux over standing senescent vegetation. We assume that the temperature of well-watered/unstressed green vegetation is close to air temperature meaning that the unstressed green vegetation sensible heat flux is neglected. This assumption is one of the main hypotheses of most contextual models such as S-SEBI (Roerink et al., 2000) or SEBAL (Bastiaanssen et al., 1998). SEB-4S is thus expected to overestimate sensible heat flux and reciprocally to underestimate ET in the case where leaf temperature is below air temperature especially under low vapor pressure deficit. Further developments of SEB-4S may address this issue by replacing EF with EE (Moran et al., 1994) or using the Priestley-Taylor formulation (Jiang and Islam, 1999). 
Similarly, the decomposition of surface latent heat flux into four components gives:

$$
L E=L E_{s}+L E_{v g u}+L E_{v g n}+L E_{v s s}
$$

with $L E_{s}\left(\mathrm{Wm}^{-2}\right)$ being the soil latent heat flux, $L E_{v g u}\left(\mathrm{Wm}^{-2}\right)$ the latent heat flux over unstressed green vegetation, $L E_{v g n}\left(\mathrm{Wm}^{-2}\right)$ the latent heat flux over non-transpiring green vegetation, and $L E_{v s s}\left(\mathrm{Wm}^{-2}\right)$ the latent heat flux over standing senescent vegetation. Consistent with the definition of non-transpiring green and senescent vegetation, $L E_{v g n}$ and $L E_{v s s}$ are both set to zero.

Over bare soil, the energy budget can be written as:

$$
R n_{s}-G=H_{s}+L E_{s}
$$

with

$$
L E_{s}=\operatorname{SEF}\left(R n_{s}-G\right)
$$

with SEF being the soil evaporative fraction.

Over unstressed green vegetation, the energy budget can be written as:

$$
R n_{v g u}=L E_{v g u}
$$

281 Over non-transpiring green vegetation, the energy budget can be written 2 as:

$$
R n_{v g n}=H_{v g n}
$$


Over standing senescent vegetation, the energy budget can be written as:

$$
R n_{v s s}=H_{v s s}
$$

Surface net radiation in Equation (4) is estimated as:

$$
R n=(1-\alpha) R_{g}+\epsilon\left(R_{a}-\sigma T^{4}\right)
$$

285

293

$$
\Gamma=\Gamma_{\mathbf{v g}}+\left(1-f_{v g}\right)\left(\boldsymbol{\Gamma}_{\mathbf{s}}-\boldsymbol{\Gamma}_{\mathbf{v g}}\right)
$$


with $\boldsymbol{\Gamma}_{\mathrm{vg}}$ and $\boldsymbol{\Gamma}_{\mathrm{s}}$ being empirical parameters set to 0.05 (Monteith, 1973) and 0.32 (Kustas and Daughtry, 1989) respectively (Su, 2002). To take advantage of the four-source representation of SEB-4S, a second formulation is tested:

$$
\Gamma^{\prime}=\boldsymbol{\Gamma}_{\mathbf{v g}}+\left(1-f_{v g u}-f_{s} \mathrm{SEF}\right)\left(\boldsymbol{\Gamma}_{\mathbf{s}}-\boldsymbol{\Gamma}_{\mathbf{v g}}\right)
$$

The physical rationale of $\Gamma^{\prime}$ is that $G$ is expected to vary with soil temperature gradient, which is inversely related to soil moisture availability. In Equation (17), soil moisture availability is approximated by a first-guess EF computed as $f_{v g u}+f_{s} \mathrm{SEF}$. Note that $\Gamma$ and $\Gamma^{\prime}$ formulations are equal in the case where $f_{v g n}=f_{s}$ SEF. Tanguy et al. (2012) have recently proposed a parameterization of $G$ as a function of EF consistent with Equation (17).

\subsection{Model assumptions}

The component fractions in Equation (4) and (17) and SEF in Equations (8) and (17) are derived from seven endmembers: the soil temperature $\mathbf{T}_{\mathbf{s}, \max }$ corresponding to $\mathrm{SEF}=0$, the soil temperature $\mathbf{T}_{\mathbf{s}, \min }$ corresponding to $\mathrm{SEF}=1$, the temperature of well-watered/unstressed vegetation $\mathbf{T}_{\mathbf{v}, \min }$, the temperature of non-transpiring green or senescent vegetation $\mathbf{T}_{\mathbf{v}, \max }$, the soil albedo $\alpha_{\mathbf{s}}$, the green vegetation albedo $\alpha_{\mathbf{v g}}$, and the senescent vegetation albedo $\alpha_{\mathbf{v s}}$. Below is a summary of the assumptions made in the following subsections to derive the seven parameters from solar/thermal remote sensing data.

The assumptions common to other image-based approaches such as WDI and S-SEBI are: 
- Atmospheric conditions are relatively homogeneous over the study area (Tang et al., 2010; Long and Singh, 2012, e.g.).

- The minimum temperature of green vegetation is close to air temperature (Carlson et al., 1995; Prihodko and Goward, 1997; Bastiaanssen et al., 1998). Note that this assumption relates both to well-watered green vegetation, which may have a physical temperature slightly below air temperature due to the evaporation of intercepted water and/or advection phenomenon, and to unstressed (fully transpiring) vegetation, which may have a physical temperature slightly above air temperature due to minimum stomatal resistance.

- The four temperature endmembers are representative of extreme conditions over the study area at the time of thermal sensor overpass. This notably implies that the aerodynamic resistance to heat transfer is assumed to be approximately uniform by fractional vegetation cover class. Although this assumption is implicit in all image-based algorithms, it is rarely mentioned in the literature.

- The impact of the spatial variability of surface soil moisture (Idso et al., 1975) and roughness (Matthias et al., 2000) on soil albedo is neglected, meaning that the soil albedo over dry or wet soil surfaces can be approximated to $\alpha_{\mathbf{s}}$. This assumption is implicit in S-SEBI because the EF is computed for a fixed (not variable) $\alpha$ value (Roerink et al., 2000).

- Component temperatures are linearly related to component fractions (Merlin and Chehbouni, 2004; Anderson et al., 2007; Long and Singh, 2012). 
The three assumptions specific to SEB-4S are:

- $\alpha_{\mathbf{v g}}$ is approximately the same for different crops. Green crop albedo varies mainly within $0.16-0.22$, with a mean value of about 0.19 (Kondratyev et al., 1982; Hansen, 1993; Campbell and Norman, 1998).

- $\alpha_{\mathbf{s}}$ is not larger than $\alpha_{\mathbf{v g}}$. As described in the following subsections, the assumption $\alpha_{\mathbf{s}} \leq \alpha_{\mathbf{v g}}$ is essential for drawing the polygon in the $T-\alpha$ space. This assumption generally applies to brown agricultural soils, especially to the Yaqui area where the top 0-20 $\mathrm{cm}$ soil was classified as clay. Soil albedo typically ranges from 0.08 to 0.14 for clay and from 0.10 to 0.20 for clay loam (Ten Berge, 1986). Further developments of SEB-4S will integrate the effects of bright soils (e.g. sands) in the modelling approach.

- $\alpha_{\mathbf{v s}}$ is larger than $\alpha_{\mathbf{v g}}$. Most plants change color when they mature and enter senescence stage, which is generally associated with an increase of vegetation albedo under dry conditions (Kondratyev et al., 1982). In particular, the albedo of cereal stubble (straw stalks left standing in the paddock) typically reaches values larger than 0.30 (Piggin and Schwerdtfeger), 1973; Merlin et al., 2010).

\subsection{Estimating albedo endmembers}

$\alpha_{\mathbf{s}}$ is estimated as the minimum $\alpha$ at the time of satellite overpass. The mean and standard deviation of $\alpha_{\mathbf{s}}$ is estimated as 0.09 and 0.01 respectively, which is fully consistent with values reported in the literature for clay (Ten Berge, 1986). $\alpha_{\mathbf{v g}}$ is estimated as the temporal mean (over different 
dates) of the $\alpha$ corresponding to the minimum $T$ within the observation scene $\left(\alpha_{\mathbf{v g}}=0.19\right)$. Note that the standard deviation of daily green vegetation albedo is estimated as 0.03 , which is fully consistent with values reported in the literature for fully covering green crops (Kondratyev et al., 1982; Hansen, 1993; Campbell and Norman, 1998). $\alpha_{\mathbf{v s}}$ is estimated as the maximum $\alpha$ within the observation scene and for the entire agricultural season $\left(\alpha_{\mathbf{v s}}=0.39\right)$. Note that the mean and standard deviation of daily maximum albedo is 0.29 and 0.07 , respectively. The large temporal variability of daily maximum albedo is explained by the great increase in $\alpha$ during the senescence period. Figure 2 plots $T$ as a function of $\alpha$ and illustrates the location of $\alpha_{\mathbf{s}}, \alpha_{\mathbf{v g}}$, and $\alpha_{\mathbf{v s}}$ for $T$ and $\alpha$ data on 27 April 2008.

\subsection{Estimating temperature endmembers}

The four temperature endmembers composed of $\mathbf{T}_{\mathbf{s}, \max }, \mathbf{T}_{\mathbf{s}, \mathbf{m i n}}, \mathbf{T}_{\mathbf{v}, \min }$, and $\mathbf{T}_{\mathbf{v}, \max }$ are estimated by providing an original consistent interpretation of the $T-\alpha$ and $T-f_{v g}$ polygons. In particular, a correspondance is built between the four vertices of the $T-\alpha$ and $T-f_{v g}$ polygons as illustrated in Figure 2 and explained below. For clarity, a schematic chart is presented in Figure 3 .

The four edges of the $T-\alpha$ polygon are interpreted as "bare soil" between A and B, "wet surface" between B and C, "full-cover vegetation" between $\mathbf{C}$ and $\mathbf{D}$, and "dry surface" between $\mathbf{D}$ and $\mathbf{A}$. The four edges of the $T-f_{v g}$ polygon are interpreted as "bare soil or mixed soil and senescent vegetation" between $\mathbf{A}$ and B, "wet surface" between $\mathbf{B}$ and $\mathbf{C}$, "full-cover green vegetation" between $\mathbf{C}$ and $\mathbf{D}$, and "dry surface" between $\mathbf{D}$ and $\mathbf{A}$. Note that the segments $[\mathbf{A B}]$ and $[\mathbf{C D}]$ are interpreted differently in the $T-\alpha$ and 
$T-f_{v g}$ polygons cover because $\alpha$ is a signature of total (green plus senescent) vegetation cover while $f_{v g}$ (via the NDVI) is a signature of green vegetation cover only.

Each polygon can provide an estimate of the four temperature endmembers. In the $T-\alpha$ polygon, $\mathbf{T}_{\mathbf{s}, \max }$ can be set to the maximum $T, \mathbf{T}_{\mathbf{s}, \min }$ to the minimum $T$ at minimum $\alpha, \mathbf{T}_{\mathbf{v}, \min }$ to the minimum $T$, and $\mathbf{T}_{\mathbf{v}, \mathbf{m a x}}$ to the $T$ at maximum $\alpha$. Similarly, in the $T-f_{v g}$ polygon, $\mathbf{T}_{\mathbf{s}, \max }$ can be set to the maximum $T, \mathbf{T}_{\mathbf{s}, \mathbf{m i n}}$ to the minimum $T$ at minimum $f_{v g}, \mathbf{T}_{\mathbf{v}, \mathbf{m i n}}$ to the minimum $T$, and $\mathbf{T}_{\mathbf{v}, \max }$ to the maximum $T$ at maximum $f_{v g}$. However, a different approach is preferred herein to improve the robustness, especially in the environments where all surface conditions (dry, wet, bare, full-cover) are not necessarily met. In this paper, the procedure for automatically estimating temperature endmembers is based on the consistency between both $T-\alpha$ and $T-f_{v g}$ polygons:

- in the $T-\alpha$ polygon, estimates of the minimum soil temperature $\left(\mathbf{T}_{\mathbf{s}, \mathbf{m i n}, \mathbf{1}}\right.$ at $\left.\alpha=\alpha_{\mathbf{s}}\right)$ and minimum vegetation temperature $\left(\mathbf{T}_{\mathbf{v}, \mathbf{m i n}, \mathbf{1}}\right.$ at $\alpha=\alpha_{\mathbf{v g}}$ ) are obtained by drawing a line passing through the two points belonging to the "wet surface" edge, and estimates of maximum soil temperature $\left(\mathbf{T}_{\mathbf{s}, \mathbf{m a x}, \mathbf{1}}\right.$ at $\left.\alpha=\alpha_{\mathbf{s}}\right)$ and maximum vegetation temperature $\left(\mathbf{T}_{\mathbf{v}, \mathbf{m a x}, \mathbf{1}}\right.$ at $\left.\alpha=\alpha_{\mathbf{v s}}\right)$ are obtained by drawing a line passing through the two points belonging to the "dry surface" edge. The "wet surface" edge is defined as the line passing through the point $\left(\alpha_{\mathbf{v g}}, \mathbf{T}_{\mathbf{m i n}}\right)$, with $\mathbf{T}_{\mathbf{m i n}}$ being the minimum $T$, and the point with $\alpha<\alpha_{\mathbf{v g}}$ and $f_{v g}<\mathbf{f}_{\mathbf{v g} \text {,ENDMB }}$ such as the slope of the line is maximum (meaning that all the other data points are located above the 
"wet surface" edge). $\mathbf{f}_{\mathbf{v g}, \mathbf{E N D M B}}$ is a threshold value (set to 0.5 in this study) which stabilizes the determination of the slope. The use of $\mathbf{f}_{\mathrm{vg} \text {,ENDMB }}$ is needed to avoid defining a line (the wet edge in this case) from two data points very close together (Merlin et al., 2012b). Similarly, the "dry surface" edge is defined as the line passing through the point $\left(\alpha_{\mathbf{s}}, \mathbf{T}_{\max }\right)$, with $\mathbf{T}_{\max }$ being the maximum $T$, and the point with $\alpha>\alpha_{\mathbf{v g}}$ such as the slope of the line is maximum (meaning that all the other data points are located below the "dry surface" edge).

- in the $T-f_{v g}$ polygon, alternative estimates of the minimum soil temperature $\left(\mathbf{T}_{\mathbf{s}, \mathbf{m i n}, \mathbf{2}}\right.$ at $\left.f_{v g}=0\right)$ and minimum vegetation temperature $\left(\mathbf{T}_{\mathbf{v}, \mathbf{m i n}, \mathbf{2}}\right.$ at $\left.f_{v g}=1\right)$ are obtained by drawing a line passing through the two points belonging to the "wet surface" edge, and alternative estimates of maximum soil temperature $\left(\mathbf{T}_{\mathbf{s , m a x}, \mathbf{2}}\right.$ at $\left.f_{v g}=0\right)$ and maximum vegetation temperature $\left(\mathbf{T}_{\mathbf{v}, \mathbf{m a x}, \mathbf{2}}\right.$ at $\left.f_{v g}=1\right)$ are obtained by drawing a line passing through the two points belonging to the "dry surface" edge. The "wet surface" edge is defined as the line passing through the point $\left(1, \mathbf{T}_{\mathbf{m i n}}\right)$ and the point with $f_{v g}<\mathbf{f}_{\mathbf{v g} \text {,ENDMB }}$ such as the slope of the line is maximum (meaning that all the other data points are located above the "wet surface" edge). Similarly, the "dry surface" edge is defined as the line passing through the point $\left(0, \mathbf{T}_{\max }\right)$ and the point with $f_{v g}>\mathbf{f}_{\mathbf{v g} \text {,ENDMB }}$ such as the slope of the line is maximum (meaning that all the other data points are located below the "dry surface" edge).

- an estimate of the four temperature endmembers is obtained by aver- 
aging the two temperature endmembers sets 1 and 2:

$$
\begin{aligned}
& \mathrm{T}_{\mathrm{s}, \max }=\mathrm{T}_{\mathrm{s}, \max , 1}=\mathrm{T}_{\mathrm{s}, \max , 2}=\mathrm{T}_{\max }
\end{aligned}
$$

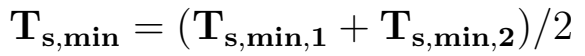

$$
\begin{aligned}
& \mathrm{T}_{\mathrm{v}, \min }=\mathrm{T}_{\mathrm{v}, \min , 1}=\mathrm{T}_{\mathrm{v}, \min , 2}=\mathrm{T}_{\min } \\
& \mathbf{T}_{\mathbf{v}, \max }=\left(\mathbf{T}_{\mathbf{v}, \max , \mathbf{1}}+\mathbf{T}_{\mathbf{v}, \max , \mathbf{2}}\right) / 2
\end{aligned}
$$

\subsection{Estimating component temperatures}

Component temperatures are defined in Table 2, They are derived from the temperature and albedo endmembers estimated previously. The green vegetation temperature $T_{v g}$ is computed from the $T-f_{v g}$ polygon. The total (green plus senescent) vegetation temperature $T_{v}$ is computed from the $T-\alpha$ polygon. The soil temperature $T_{s}$ is computed as the residual term.

Component temperatures $T_{v g}$ and $T_{v}$ are estimated as the most probable green and total vegetation temperature, respectively. Most probable temperatures are defined as in the hourglass approach in Moran et al. (1994), Merlin et al. (2012b) and Merlin et al. (2013). They correspond to the average of the minimum and maximum physically acceptable temperatures, given the constraints imposed by the vertices of the polygons. Below is explained how in practice the minimum and maximum acceptable green (or total) vegetation temperatures are determined from the location of a given data point 
452

$\left(f_{v g}, T\right)$ in the $T-f_{v g}$ space (or from the location of a given data point $(\alpha, T)$ in the $T-\alpha$ space).

\subsubsection{Estimating $T_{v g}$ in the $T-f_{v g}$ polygon}

By plotting the diagonals of the quadrilateral defined in the $T-f_{v g}$ space, four areas are distinguished (Merlin et al., 2012b). The procedure for estimating $T_{v g}$ from the $T-f_{v g}$ polygon is illustrated in Figure 4 and described below:

- For a given data point located in zone Z1:

$$
T_{v g}=\left(\mathbf{T}_{\mathbf{v}, \min }+\mathbf{T}_{\mathbf{v}, \max }\right) / 2
$$

- For a given data point located in zone Z2:

$$
T_{v g}=\left(\mathbf{T}_{\mathbf{v}, \min }+T_{v g, \max }\right) / 2
$$

461 with $T_{v g, \max }$ being the green vegetation temperature associated with $f_{v s s}=0$ and $\mathrm{SEF}=1\left(T_{s}=\mathbf{T}_{\mathbf{s}, \min }\right)$.

- For a given data point located in zone Z3:

$$
T_{v g}=\left(T_{v g, \min }+T_{v g, \max }\right) / 2
$$

w64 with $T_{v g, \min }$ being the green vegetation temperature associated with $f_{v s s}=0$ and $\mathrm{SEF}=0\left(T_{s}=\mathbf{T}_{\mathbf{s}, \mathbf{m a x}}\right)$. 
- For a given data point located in zone Z4:

$$
T_{v g}=\left(T_{v g, \min }+\mathbf{T}_{\mathbf{v}, \max }\right) / 2
$$

In zone Z1, $T$ is mainly controlled by $T_{s}$ (via soil evaporation) and the associated $T_{v g}$ is uniform. In zone $\mathrm{Z} 3, T$ is mainly controlled by $T_{v g}$ (via vegetation transpiration) and the associated $T_{s}$ is uniform. In zones $\mathrm{Z} 2$ and Z4, T is controlled by both $T_{s}$ and $T_{v g}$ (Merlin et al., 2012b).

\subsubsection{Estimating $T_{v}$ in the $T-\alpha$ polygon}

The $T-\alpha$ polygon is used to estimate $T_{v}$. The rationale for choosing the $T-\alpha$ instead of the $T-f_{v g}$ polygon is that $\alpha$ is sensitive to both green and senescent vegetation whereas $f_{v g}$ (via NDVI) does not differentiate between soil and senescent vegetation (Merlin et al., 2010). The procedure for estimating $T_{v}$ from the $T-\alpha$ polygon is similar to the hourglass approach. It is illustated in Figure 5 and described below:

- For a given data point located in zone Z1:

$$
T_{v}=\left(\mathbf{T}_{\mathbf{v}, \min }+\mathbf{T}_{\mathbf{v}, \max }\right) / 2
$$

- For a given data point located in zone Z2, vegetation temperature is:

$$
T_{v}=\left(\mathbf{T}_{\mathbf{v}, \min }+T_{v, \max }\right) / 2
$$

wo with $T_{v, \max }$ being the vegetation temperature associated with $\mathrm{SEF}=1$ $\left(T_{s}=\mathbf{T}_{\mathbf{s}, \min }\right)$. 
85

- For a given data point located in zone Z3:

$$
T_{v}=\left(T_{v, \min }+T_{v, \max }\right) / 2
$$

83

84

- For a given data point located in zone Z4:

$$
T_{v}=\left(T_{v, \min }+\mathbf{T}_{\mathbf{v}, \max }\right) / 2
$$

\subsubsection{Estimating $T_{s}$}

$T_{s}$ is estimated as the residual term:

$$
T_{s}=\frac{T-f_{v} T_{v}}{1-f_{v}}
$$

Soil temperature from Equation (30) is expected to be more accurate for $f_{v} \leq 0.5$ than for $f_{v}>0.5$, and is undetermined for $f_{v}=1$. In particular, the soil temperature may get unphysical large values when $f_{v}$ is close to 1 . To make the algorithm numerically stable, the upper limit of retrieved $T_{s}$ is set to $\mathbf{T}_{\mathbf{s}, \mathbf{m a x}}$. Note that uncertainties in $T_{s}$ for large $f_{v}$ values do not impact ET estimates because $f_{s}$ is close to zero in this case.

\subsection{Estimating SEF}

SEF in Equations (8) and (17) is estimated as:

$$
\mathrm{SEF}=\frac{\mathbf{T}_{\mathbf{s}, \max }-T_{s}}{\mathbf{T}_{\mathbf{s}, \max }-\mathbf{T}_{\mathbf{s}, \min }}
$$




\subsection{Estimating component fractions}

The four component fractions $f_{s}, f_{v g u}, f_{v g n}$, and $f_{v s s}$ in Equation (4) are derived by solving four equations.

Green vegetation fractions $f_{v g u}$ and $f_{v g n}$ are expressed as a function of $f_{v g}, T_{v g}$ and vegetation temperature endmembers:

$$
f_{v g} T_{v g}=f_{v g u} \mathbf{T}_{\mathbf{v}, \min }+f_{v g n} \mathbf{T}_{\mathbf{v}, \max }
$$

with $T_{v g}$ being computed in Equations (22-25). Since $f_{v g u}+f_{v g n}=f_{v g}$, one is able to solve $f_{v g u}$ :

$$
f_{v g u}=\frac{\mathbf{T}_{\mathbf{v}, \text { max }}-T_{v g}}{\mathbf{T}_{\mathbf{v}, \text { max }}-\mathbf{T}_{\mathbf{v}, \text { min }}} f_{v g}
$$

and $f_{v g n}$ :

$$
f_{v g n}=f_{v g}-f_{v g u}
$$

The total fractional vegetation cover $f_{v}$ (equal to $f_{v g u}$ plus $f_{v g n}$ plus $f_{v s s}$ ) is expressed as a function of $T_{v}, \alpha$, and albedo and temperature endmembers. In Figure 6, $f_{v}$ is equal to the ratio IJ/IK with $\mathrm{J}$ being located at $(\alpha, T), \mathrm{I}$ located at $\left(\alpha_{\mathbf{s}}, T_{s}\right)$, and $\mathrm{K}$ located at $\left(\alpha_{v}, T_{v}\right)$ with $\alpha_{v}$ being the vegetation albedo, and $T_{v}$ the vegetation temperature computed in Equations (26-29). Both I and K are placed on the polygon of Figure 6 using the same approach adopted to compute $T_{v}$. Given that $(\mathbf{A B})$ is parallel to y-axis, one can deduce that:

$$
f_{v}=\frac{\alpha-\alpha_{\mathbf{s}}}{\alpha_{v}-\alpha_{\mathbf{s}}}
$$


with $\alpha_{v}$ being a function of $T_{v}$. On the full-cover edge [CD], one writes:

$$
T_{v}=\mathbf{T}_{\mathbf{v}, \min }+\frac{\alpha_{v}-\alpha_{\mathbf{v g}}}{\alpha_{\mathbf{v s}}-\alpha_{\mathbf{v g}}}\left(\mathbf{T}_{\mathbf{v}, \text { max }}-\mathbf{T}_{\mathbf{v}, \text { min }}\right)
$$

By inverting Equation (36), one obtains:

$$
\alpha_{v}=\alpha_{\mathbf{v g}}+\frac{T_{v}-\mathbf{T}_{\mathbf{v}, \text { min }}}{\mathbf{T}_{\mathbf{v}, \max }-\mathbf{T}_{\mathbf{v}, \min }}\left(\alpha_{\mathbf{v s}}-\alpha_{\mathbf{v g}}\right)
$$

Hence, $f_{v}$ is derived by injecting Equation (37) into Equation (35).

$f_{v s s}$ is estimated as the residual term of $f_{v}$ :

$$
f_{v s s}=f_{v}-f_{v g}
$$

$f_{s}$ is estimated as the residual term:

$$
f_{s}=1-f_{v}
$$

\section{Image-based models}

Two common image-based models are implemented as benchmarks to evaluate the performance of SEB-4S in estimating EF/ET. Although the $T-\alpha$ image-based model is similar to S-SEBI and the $T-f_{v g}$ image-based model similar to WDI, the objective is not to intercompare SEB-4S, S-SEBI and WDI, but rather to compare SEB-4S with image-based ET models having the same general structure as SEB-4S. In particular, the wet and dry edges are determined from the same temperature endmembers set in each case, and both image-based models express ET as a function of EF as in SEB-4S (instead of EE for WDI). 


\section{1. $T-\alpha$ image-based model}

The $T-\alpha$ image-based model is derived from S-SEBI (Roerink et al., 2000). In S-SEBI, linear relationships are established between $T$ and $\alpha$ for the wet and the dry surface cases. The wet and dry surface lines are defined as the lower and upper limit of the $T-\alpha$ space, respectively. In this study, the wet and dry lines are set to (CD) and (AD), respectively (see Figure 2). ET is then estimated as EF times the surface available energy $(R n-G)$, with EF being computed as:

$$
\mathrm{EF}=\frac{T_{\max }-T}{T_{\max }-T_{\min }}
$$

with $T_{\max }$ being the $T$ if the pixel surface was fully dry, and $T_{\min }$ the $T$ if the pixel surface was fully wet. $T_{\max }$ and $T_{\min }$ are computed at $\alpha$ on the dry and wet line, respectively (see Figure $7 \mathrm{a}$ ).

\section{2. $T-f_{v g}$ image-based model}

The $T-f_{v g}$ image-based model is derived from the WDI (Moran et al., 1994). In WDI, linear relationships are established between $T$ and $f_{v g}$ for the wet and the dry surface cases. The wet and dry surface lines are defined as the lower and upper limit of the $T-f_{v g}$ space, respectively. In this study, the wet and dry lines are set to (BC) and (AD), respectively (see Figure 2). In WDI, ET is estimated as:

$$
L E=(1-\mathrm{WDI}) L E p
$$

545 with $L E p\left(\mathrm{Wm}^{-2}\right)$ being the potential ET. Herein, $L E p$ is replaced by $R n-G$ in Equation (41) to be consistent with both SEB- 4 S and the $T-\alpha$ 
image-based model. The factor $(1-$ WDI) is estimated as EF in Equation (40) with $T_{\max }$ and $T_{\min }$ being computed at $f_{v g}$ on the dry and wet line, respectively (see Figure $7 \mathrm{~b}$ ).

\section{Application}

The simulation results of SEB-4S, the $T-\alpha$ image-based model, and the $T-f_{v g}$ image-based model are compared with the in situ measurements collected by the six flux stations. The objective is to evaluate model performances in terms of ET estimates in a range of surface conditions. Comparisons are made at the pixel scale by extracting the ASTER thermal pixels including a flux station.

\subsection{Temperature endmembers and component fractions}

The algorithm for estimating temperature endmembers is run on the seven ASTER overpass dates. To assess the consistency between the temperature endmembers set 1 (derived from the $T-\alpha$ polygon) and 2 (derived from the $T-f_{v g}$ polygon), Figure 8 plots $\mathbf{T}_{\mathbf{s}, \mathbf{m i n}, \mathbf{2}}$ versus $\mathbf{T}_{\mathbf{s}, \mathbf{m i n}, \mathbf{1}}$ and $\mathbf{T}_{\mathbf{v}, \mathbf{m a x}, \mathbf{2}}$ versus $\mathbf{T}_{\mathbf{v}, \mathbf{m a x}, \mathbf{1}}$ (remind that by definition $\mathbf{T}_{\mathbf{s , m a x}, \mathbf{2}}=\mathbf{T}_{\mathbf{s}, \mathbf{m a x}, \mathbf{1}}$ and $\left.\mathbf{T}_{\mathbf{v}, \mathbf{m i n}, \mathbf{2}}=\mathbf{T}_{\mathbf{v}, \mathbf{m i n}, \mathbf{1}}\right)$. In terms of minimum soil temperature, temperature endmembers sets 1 and 2 are remarkably consistent with a correlation coeffient and slope of the linear regression between $\mathbf{T}_{\mathbf{s , m i n}, \mathbf{2}}$ and $\mathbf{T}_{\mathbf{s}, \mathbf{m i n}, \mathbf{1}}$ of 0.91 and 0.83 , respectively. In terms of maximum vegetation temperature, temperature endmembers sets 1 and 2 are still consistent but the difference between both data sets is larger with a correlation coeffient and slope of the linear regression between $\mathbf{T}_{\mathbf{v}, \mathbf{m a x}, \mathbf{2}}$ and $\mathbf{T}_{\mathbf{v}, \mathbf{m a x}, \mathbf{1}}$ of 0.50 and 0.39 , respectively. Overall the temperature endmembers estimated from the $T-\alpha$ and $T-f_{v g}$ 
polygons have an absolute mean difference of $0.5^{\circ} \mathrm{C}$ and $2.5^{\circ} \mathrm{C}$ for $\mathbf{T}_{\mathbf{s} \text {,min }}$ and $\mathbf{T}_{\mathbf{v}, \max }$, respectively. These results justify the strategy to derive $\mathbf{T}_{\mathbf{s}, \min }$ and $\mathbf{T}_{\mathbf{v}, \max }$ from the average of temperature endmembers sets 1 and 2 .

Figure 9 plots side by side the $T-\alpha$ and $T-f_{v g}$ spaces overlaid with the polygons drawn from the retrieved temperature endmembers $\mathbf{T}_{\mathbf{s}, \mathbf{m a x}}, \mathbf{T}_{\mathbf{s}, \min }$, $\mathbf{T}_{\mathbf{v}, \text { min }}$ and $\mathbf{T}_{\mathbf{v}, \max }$. One observes that the shape of both the $T-\alpha$ and $T-f_{v g}$ spaces significantly varies from date to date. In particular, the shape of the $T-\alpha$ space at the end (on 13 May 2008) and at the beginning (on 30 December 2007) of the agricultural season are very distinct due to a different range of $\alpha$ values. This is notably explained by the presence of bright senescent vegetation towards the end of the agricultural season. However, despite the strong temporal variability of $T-\alpha$ spaces, the $T-\alpha$ polygons automatically retrieved by the temperature endmembers algorithm are relatively stable, meaning that the four edges are robustly estimated across the entire agricultural season. When comparing the $T-\alpha$ with the $T-f_{v g}$ spaces, each polygon consistently describes the contour of the data points in both the $T-\alpha$ and $T-f_{v g}$ spaces. This justifies the approach for estimating temperature endmembers based on a synergistic use of $T-\alpha$ and $T-f_{v g}$ spaces.

Given the previously retrieved four temperature endmembers, one is able to estimate the four component fractions at ASTER thermal sensor resolution over the 16 by $10 \mathrm{~km}$ area. Figure 10 presents the images of $f_{s}, f_{v g u}, f_{v g n}$, and $f_{v s s}$ on each of the seven ASTER overpass dates. They illustrate both the seasonality of canopies throughout the agricultural period and the high variability of vegetation cover within the study area. The estimated fraction 
of non-transpiring green vegetation $\left(f_{v g n}\right)$ is generally low over the irrigated area, with a mean maximum on 11 April before the senescence starts for the majority of crops.

\subsection{Net radiation and ground heat flux}

Figure 11 plots the simulated versus observed net radiation at the six flux stations. Since wheat is the dominant cropping type within the area, results for station 5 and 6 are highlighted with black markers. Statistics are reported in Table 3 in terms of correlation coefficient, root mean square difference, mean difference, and slope of the linear regression between simulated and observed data. A positive bias of $24 \mathrm{Wm}^{-2}$ on $R n$ was found in Chirouze et al. (2013). In this paper, the absence of bias (estimated as -3 $\mathrm{Wm}^{-2}$ ) on $R n$ can be explained by the use of ASTER-derived emissivity. The mean ASTER-derived $\epsilon$ is about 0.95, which is significantly smaller that the default value (0.98) used in Chirouze et al. (2013). The slight difference in $R n$ estimates can also be explained by the fact that in this paper $R_{a}$ was modeled using the formulation in Brutsaert (1975), whereas the observed $R_{a}$ was used in Chirouze et al. (2013).

Ground heat flux is computed as a fraction $\left(\Gamma\right.$ or $\left.\Gamma^{\prime}\right)$ of net radiation. In order to identify the impact on $G$ of uncertainties in $R n$ and in $\Gamma$ or $\Gamma^{\prime}$, four different expressions of $G$ are derived using $\Gamma$ or $\Gamma^{\prime}$, and observed or simulated $R n$. Figure 12 plots the simulated versus observed ground heat flux at the six flux stations, and error statistics are provided in Table 3 . One observes that the $\Gamma^{\prime}$ formulation provides more accurate $G$ estimates than the $\Gamma$ formulation. Consequently, the explicit representation in SEB$4 \mathrm{~S}$ of bare soil, its water status (via SEF), and unstressed green vegetation 
helps model soil heat flux. By comparing the error statistics for $G$ simulated using observed and simulated $R n$, one observes that errors in modeled $R n$ are responsible for a $10 \%$ error on simulated $G$.

Note that the slope of the linear regression between simulated and observed $G$ is generally low. This can be explained by a significant overestimation of $G$ measurements at station 3 (chickpea) (Chirouze et al., 2013). By removing data from station 3, the root mean square difference between simulated and observed $G$ decreases from 46 to $34 \mathrm{Wm}^{-2}$ (for the case $\Gamma^{\prime}$ and observed $R n$ ). The low slope of the linear regression between simulated and observed $G$ can also be explained by uncertainties in $f_{s}$ and SEF. Even if SEB-4S provides an estimate of $f_{s}$ and SEF, it is worth reminding that $f_{s}$ is computed as the residual term of component fractions, which may integrate several error sources, and SEF is computed from the retrieved soil temperature $T_{s}$, which systematically integrates errors in $T_{v}$ estimated as the most probable (not the actual) vegetation temperature. In fact, better constraining soil heat fluxes would require knowledge of soil temperature (Moran et al., 1994), or soil evaporative efficiency or near-surface soil moisture (Merlin et al., 2012a).

The $G$ formulation corresponding to $\Gamma^{\prime}$ and simulated $R n$ is used in the following subsections as the $G$ component of all three (SEB-4S, $T-\alpha$ imagebased, $T-f_{v g}$ image-based) surface energy balance models.

\subsection{ET}

Figure 13 plots the ET simulated by the $T-\alpha$ image-based model, the $T-f_{v g}$ image-based, and SEB-4S versus measurements at the six stations. To quantify the impact of the modeling of available energy $(R n-G)$ on ET 
predictions, Figures 13a,b,c present the ET modeled from the observed available energy, and Figures 13d,e,f present the ET modeled from the modeled available energy. Error statistics are provided in Table 4 in terms of correlation coefficient, root mean square difference, mean difference, and slope of the linear regression between simulated and observed $L E$. One observes that uncertainties in modeled available energy slightly degrade model predictions, but the approach for estimating EF has a much more significant impact on $L E$ estimates. In terms of correlation coefficient for instance, modeled available energy is responsible for a $0.00-0.03$ difference, while modeled evaporative fraction is responsible for a $0.08-0.14$ difference. Hence, improving EF representation is a key step in improving ET models. Overall, SEB-4S improves the correlation coefficient and slope of the linear regression between simulated and observed ET from $0.78-0.81$ to 0.89 , and from $0.55-0.63$ to 0.90 , respectively. The improvement reaches about $100 \mathrm{~W} \mathrm{~m}^{-2}$ at low values and about $100 \mathrm{~W} \mathrm{~m}^{-2}$ at the seasonal peak of ET as compared with both $T-f_{v g}$ and $T-\alpha$ image-based models.

Figure 14 presents the images on the seven ASTER overpass dates of the ET simulated by the $T-\alpha$ image-based model, the $T-f_{v g}$ imagebased, and SEB-4S. A visual comparison indicates that the main differences between the three models occur during the second half of the agricultural season when the evaporative demand and the mean fraction of senescent vegetation are larger. The $T-f_{v g}$ image-based model and SEB-4S have a similar behavior before the ET peak in April. However, significant differences between $T-\alpha$ image-based model and SEB-4S are observable all along the agricultural season, including the period before the ET peak. Especially 
the $T-\alpha$ image-based model seems to lack sensitivity over the full ET range, thus systematically overestimating low values and underestimating large values. These differences are interpreted as resulting from the physical reasoning underlying the estimation of $\mathrm{EF}$ in each of the three models. In the $T-\alpha$ image-based model, EF is computed by assuming that the wet surface edge is (CD) instead of $[\mathbf{B C}]$ in SEB-4S. In the $T-f_{v g}$ image-based model, EF is computed by assuming that the energy fluxes over senescent vegetation behave as those over bare soil. In SEB-4S, EF is computed from on a consistent physical interpretation of both $T-\alpha$ and $T-f_{v g}$ spaces, and an explicit representation of four surface components including bare soil and senescent vegetation.

\subsection{Sensitivity to $\alpha_{\mathrm{vg}}$ and $\alpha_{\mathrm{vs}}$}

In the current version of SEB-4S, the green and senescent vegetation albedos are set to constant values (0.19 and 0.39) for all crop types. One needs to assess the impact of variabilities (and uncertainties) in green and senescent vegetation albedos on ET estimates. A sensitivity analysis is undertaken by setting $\alpha_{\mathbf{v g}}$ and $\alpha_{\mathbf{v s}}$ to daily values. Daily $\alpha_{\mathbf{v g}}$ is estimated as the $\alpha$ value corresponding to the minimum $T$ on each date separately. Daily $\alpha_{\mathbf{v s}}$ is estimated as the maximum $\alpha$ value observed on each date separately. The ET simulated by SEB-4S for each parameter set is then compared with the ET simulated using the constant $\alpha_{\mathbf{v g}}$ and $\alpha_{\mathbf{v s}}$ values (originally estimated as the average of daily $\alpha_{\mathbf{v g}}$, and as the maximum value of daily $\alpha_{\mathbf{v s}}$ over the entire time series, respectively). The root mean square difference is estimated as 24, 36 and $47 \mathrm{Wm}^{-2}$ in the case of daily $\alpha_{\mathbf{v g}}$ and constant $\alpha_{\mathbf{v s}}$, daily $\alpha_{\mathbf{v s}}$ and constant $\alpha_{\mathbf{v g}}$, and both parameters estimated daily, respectively. When 
comparing simulated ET with in situ measurements, the root mean square difference and correlation coefficient are $75 \mathrm{Wm}^{-2}$ and 0.92 for constant (original) parameters, $75 \mathrm{Wm}^{-2}$ and 0.92 for daily $\alpha_{\mathbf{v g}}$ and constant $\alpha_{\mathbf{v s}}, 87 \mathrm{Wm}^{-2}$ and 0.91 for constant $\alpha_{\mathbf{v g}}$ and daily $\alpha_{\mathbf{v s}}$, and $88 \mathrm{Wm}^{-2}$ and 0.91 for both parameters estimated daily. To evaluate the impact of potential differences of the albedo values $\left(\alpha_{\mathbf{v g}}, \alpha_{\mathbf{v s}}\right)$ for different crops, an additional sensitivity analysis is undertaken in space by artificially applying a Gaussian noise to $\alpha_{\mathbf{v g}}$ and $\alpha_{\mathbf{v s}}$ for each pixel independently. The noise amplitude (0.03 for $\alpha_{\mathbf{v g}}$ and 0.07 for $\alpha_{\mathbf{v s}}$ ) is set to the standard deviation over the entire time series of the albedo endmembers estimated on a daily basis. The root mean square difference between the ET simulated using original (undisturbed) parameters and the ET simulated using the noised parameters is estimated as $7 \mathrm{Wm}^{-2}$. Moreover, the root mean square difference and correlation coefficient between simulated and observed ET is $77 \mathrm{Wm}^{-2}$ and 0.91 for the noised dataset (as compared with $75 \mathrm{Wm}^{-2}$ and 0.92 for the original dataset). Hence the sensitivity analysis reveals that 1 ) the assumption that $\alpha_{\mathbf{v g}}$ and $\alpha_{\mathbf{v s}}$ are relatively constant is deemed acceptable in terms of simulated ET, and 2) SEB-4S is quite robust with respect to uncertainties in $\alpha_{\mathbf{v g}}$ and $\alpha_{\mathbf{v s}}$. In case a time series of solar/thermal data is not available across the agricultural season, estimating $\alpha_{\mathbf{v g}}$ and $\alpha_{\mathbf{v s}}$ on a daily basis seems to be a satisfying option.

\section{Conclusions}

An operational image-based surface energy balance model (SEB-4S) is developed from a consistent physical interpretation of the polygons obtained in the $T-\alpha$ and $T-f_{v g}$ spaces. The strength of the modeling approach 
relies on the synergy between both $T-\alpha$ and $T-f_{v g}$ polygons. Specifically, the combination of $T-\alpha$ and $T-f_{v g}$ image-based approaches allows to explicitly separate the energy fluxes of four surface components of agricultural fields including bare soil, unstressed green vegetation, non-transpiring green vegetation, and standing senescent vegetation, and to robustly retrieve temperature endmembers regardless of crop phenological stages. SEB-4S operates in five steps: 1) estimating albedo and temperature endmembers, 2) estimating component temperatures, 3) estimating SEF, 4) estimating component fractions, and 5) computing component turbulent heat fluxes as a fraction of available energy.

To test the performance of SEB-4S, a $T-\alpha$ image-based model and a $T-f_{v g}$ image-based model are implemented as benchmarks. The three models are tested over a $16 \mathrm{~km}$ by $10 \mathrm{~km}$ irrigated area in northwestern Mexico during the 2007-2008 agricultural season. Input data are composed of ASTER thermal infrared, re-sampled Formosat-2 shortwave, and stationbased meteorological data. The fluxes simulated by SEB-4S, the $T-\alpha$ image-based model, and the $T-f_{v g}$ image-based model are compared on seven ASTER overpass dates with the in situ measurements collected at six locations in the study domain. The ET simulated by SEB- $4 \mathrm{~S}$ is significantly more accurate and robust than that predicted by the models based on a single (either $T-f_{v g}$ or $T-\alpha$ ) polygon. Overall, SEB-4S improves the correlation coefficient and slope of the linear regression between simulated and observed ET from $0.78-0.81$ to 0.89 , and from $0.55-0.63$ to 0.90 , respectively. The improvement reaches about $100 \mathrm{~W} \mathrm{~m}^{-2}$ at low values and about $100 \mathrm{~W}$ $\mathrm{m}^{-2}$ at the seasonal peak of ET as compared with both $T-f_{v g}$ and $T-\alpha$ 
image-based models. These differences result from the physical reasoning underlying the estimation of $\mathrm{EF}$ in each of the three models. In the $T-\alpha$ image-based model, EF is computed by assuming that the wet surface edge is the full-cover edge of the $T-f_{v g}$ polygon. In the $T-f_{v g}$ image-based model, EF is computed by assuming that the energy fluxes over senescent vegetation behave as those over bare soil. In SEB-4S, EF is computed from a consistent physical interpretation of the edges and vertices of both $T-\alpha$ and $T-f_{v g}$ polygons, and an explicit representation of four surface components including bare soil and senescent vegetation.

In this paper, SEB-4S was successfully tested over a range of surface conditions in terms of ET. However, the energy partitioning between soil evaporation and plant transpiration was not directly validated over partially covered pixels. This point will be addressed in the near future using soil evaporation and plant transpiration measurements made independently from the tower ET observations. Although SEB-4S can be operationally applied to irrigated agricultural areas using ASTER or Landsat remote sensing data, several improvements are foreseen to extend its validity domain:

- Temperature endmembers: in this study, SEB-4S is applied to an irrigated area including a large variability of soil moisture and vegetation cover conditions. Application to other less heterogeneous (e.g. rainfed agricultural) areas or to thermal data collected at coarser spatial resolutions may induce significant uncertainties in temperature endmembers. To extend the validity domain of the temperature endmembers algorithm, one may constrain the minimum vegetation temperature by setting $\mathbf{T}_{\mathbf{v}, \min }=T_{a}$ (Merlin, 2013), and/or by using a formulation of 
aerodynamic resistance.

- Representing the sensible heat flux of a wet surface: in the current version of SEB-4S, EF is assumed to be equal to EE. This means that $H_{s}$ and $H_{v g u}$ for a well watered-surface are neglected and set to zero. Further studies may use a relationship between EF and EE.

- Linearity assumptions: SEB-4S is derived from a linearity assumption between EF and $T$, and a linearity assumption between $T$ and $T_{s}, T_{v g u}$, $T_{v g n}$, and $T_{v s s}$. Moreover, the net radiation of surface components are simply expressed as a fraction of surface net radiation. The linearity assumptions are consistent with the image-based approaches, and are supported by the good results obtained in terms of ET estimates. However, further studies should investigate step-by-step the validity of these assumptions. Especially, knowledge of component radiative properties (component emissivities, albedos, temperatures) may help improve the representation of surface fluxes.

- Soil heat and water fluxes: as indicated in the paper, better constraining the soil (temperature and fraction) component would improve the estimation of soil heat and water fluxes. We will address this issue in future studies by integrating via a soil evaporative efficiency model (Merlin et al., 2011) the near-surface soil moisture derived from passive L-band SMOS (Kerr et al., 2010, Soil Moisture and Ocean Salinity) data and subsequently disaggregated at the thermal sensor resolution (Merlin et al., 2013) and/or a near-surface soil moisture index directly derived at high resolution from active C-band Sentinel-1 data. 


\section{Acknowledgments}

795 The participants of the Yaqui 2007-2008 experiment are gratefully ac796 knowledged. This study is part of the MIXMOD-E project funded by the ${ }_{797}$ French ANR (Agence Nationale de la Recherche). 


\section{References}

Allen, R. G., Pereira, L. S., Raes, D., Smith, M., 1998. Crop evapotranspiration - Guidelines for computing crop water requirements. FAO Irrigation and drainage paper 56, FAO, Rome.

Anderson, M. C., Allen, R. G., Morse, A., Kustas, W. P., 2012. Use of Landsat thermal imagery in monitoring evapotranspiration and managing water resources. Remote Sens. Environ. 122, 50-65, doi:10.1016/j.rse.2011.08.025.

Anderson, M. C., Norman, J. M., Mecikalski, J. R., Otkin, J. A., Kustas, W. P., 2007. A climatological study of evapotranspiration and moisture stress across the continental united states based on thermal remote sensing: 1. model formulation. J. Geophys. Res. 112 (D10117), doi:10.1029/2006JD007506.

Bastiaanssen, W. G. M., Menenti, M., Feddes, R. A., Holtslag, A. A. M., 1998. A remote sensing surface energy balance algorithm for land (SEBAL) 1. Formulation. J. Hydrol. 212-213, 198-212.

Bouilloud, L., Chancibault, K., Vincendon, B., Ducrocq, V., Habets, F., Saulnier, G.-M., Anquetin, S., Martin, E., Noilhan, J., 2010. Coupling the ISBA land surface model and the TOPMODEL hydrological model for Mediterranean flash-flood forecasting: description, calibration, and validation. J. Hydrometeor. 11, 315-333.

Boulet, G., Chehbouni, A., Gentine, P., Duchemin, B., Ezzahar, J., Hadria, 
R., 2007. Monitoring water stress using time series of observed to unstressed surface temperature difference. Agri. For. Meteorol. 146, 157-172.

Brutsaert, W., 1975. On a derivable formula for long-wave radiation from clear skies. Water Resour. Res. 11 (5), 742-744.

Bsaibes, A., Courault, D., Baret, F., Weiss, M., Olioso, A., Jacob, F., Hagolle, O., Marloie, O., Bertrand, N., Desfond, V., Kzemipour, F., 2009. Albedo and LAI estimates from FORMOSAT-2 data for crop monitoring. Remote Sens. Environ. 113, 716-729, doi:10.1016/j.rse.2008.11.014.

Cammalleri, C., Anderson, M. C., Ciraolo, G., D'Urso, G., Kustas, W. P., Loggia, G. L., Minacapilli, M., 2012. Applications of a remote sensingbased two-source energy balance algorithm for mapping surface fluxes without in situ air temperature observations. Remote Sens. Environ. 124, 502-515, doi:10.1016/j.rse.2012.06.009.

Campbell, G., Norman, J., 1998. An introduction to environmental biophysics, 2nd Edition. Springer, New York, USA.

Carlson, T. N., Gillies, R. R., Schmugge, T. J., 1995. An interpretation of methodologies for indirect measurement of soil water content. Agr. For. Meteorol. 77, 191-205.

Chern, J.-S., Ling, J., Weng, S.-L., 2008. Taiwan's second remote sensing satellite. Acta Astronautica 63 (11-12), 1305-1311, doi:10.1016/j.actaastro.2008.05.022.

Chirouze, J., Boulet, G., Jarlan, L., Fieuzal, R., Rodriguez, J. C., Ezzahar, J., Er-raki, S., Bigeard, G., Merlin, O., Garatuza-Payan, J., Watts, 
C., Chehbouni, G., 2013. Inter-comparison of four remote sensing based surface energy balance methods to retrieve surface evapotranspiration and water stress of irrigated fields in semi-arid climate. Hydrol. Earth Syst. Sci. Discuss. 10, 895-963, doi:10.5194/hessd-10-895-2013.

Choi, M., Kustas, W. P., Anderson, M. C., Allen, R. G., Li, F., Kjaersgaard, J. H., 2009. An intercomparison of three remote sensing-based surface energy balance algorithms over a corn and soybean production region (Iowa, U.S.) during SMACEX. Agr. Forest Meteor. 149, 2082-2097, doi:10.1016/j.agrformet.2009.07.002.

Cleugh, H., Leuning, R., Mu, Q., Running, S., 2007. Regional evaporation estimates from flux tower and MODIS satellite data. Remote Sens. Environ. 106, 285-304.

Courault, D., Seguin, B., Olioso, A., 2005. Review on estimation of evapotranspiration from remote sensing data: from empirical to numerical modeling approaches. Irrig. Drain. Syst. 19, 223-249.

Fieuzal, R., Duchemin, B., Jarlan, L., Zribi, M., Baup, F., Merlin, O., Hagolle, O., Garatuza-Payan, J., 2011. Combined use of optical and radar satellite data for the monitoring of irrigation and soil moisture of wheat crops. Hydrol. Earth Syst. Sci. 15, 1117-1129.

Findell, K. L., Gentine, P., Lintner, B. R., Kerr, C., 2011. Probability of afternoon precipitation in eastern United States and Mexico enhanced by high evaporation. Nature Geosci. 4, 434-439. 
Galleguillos, M., Jacob, F., Prévot, L., French, A., Lagacherie, P., 2011. Comparison of two temperature differencing methods to estimate daily evapotranspiration over a Mediterranean vineyard watershed from ASTER data. Remote Sens. Environ. 115, 1326-1340.

Gillespie, A., Rokugawa, S., Matsunaga, T., Cothern, S., Hook, S., Khale, A., 1998. A temperature and emissivity separation algorithm for Advanced Spaceborne Thermal Emission and Reflection (ASTER) images. IEEE Trans. Geosci. Remote Sens. 36, 1113-1126.

Gonzalez-Dugo, M. P., Neale, C. M. U., Mateos, L., Kustas, W. P., Prueger, J. H., Anderson, M. C., Li, F., 2009. A comparison of operational remote sensing-based models for estimating crop evapotranspiration. Agr. Forest Meteor. 149, 1843-1853, doi:10.1016/j.agrformet.2009.06.012.

Gowda, P. H., Chavez, J. L., Colaizzi, P. D., Evett, S. R., Howell, T. A., Tolk, J. A., 2008. ET mapping for agricultural water management: present status and challenges. Irrig. Sci. 26, 223-237, doi:10.1007/s00271-007-00886.

Gutman, G., Ignatov, A., 1998. The derivation of the green vegetation fraction from NOAA/AVHRR data for use in numerical weather prediction models. Int. J. Remote Sens. 19, 1533-1543.

Gutmann, E. D., Small, E. E., 2007. A comparison of land surface model soil hydraulic properties estimated by invese modeling and pedotransfer functions. Water Resour. Res. 43 (W06520). 
Hain, C., Mecikalski, J., Anderson, M., 2009. Retrieval of an available waterbased soil moisture proxy from thermal infrared remote sensing. Part I: methodology and validation. J. Hydrometeor. 10, 665-683.

Hansen, V. F., 1993. Albedos. Vol. ARL-TR-57. Army Research Laboratory, US.

Idso, S. B., Jackson, R. D., Pinter, P. J., Reginato, R. J., Hatfield, J. L., 1981. Normalizing the stress-degree-day parameter for environmental variability. Agric. Meteorol. 24, 45-55.

Idso, S. B., Jackson, R. D., Reginato, R. J., Kimball, B. A., Nakayama, F. S., 1975. The dependence of soil albedo on soil water content. J. Appl. Meteor. 14, 109-113.

Jackson, R. D., Idso, S. B., Reginato, R. J., Pinter, P. J., 1981. Canopy temperature as a crop water stress indicator. Water Resour. Res. 17 (4), 1133-1138.

Jiang, L., Islam, S., 1999. A methodology for estimation of surface evapotranspiration over large areas using remote sensing observations. Geophys. Res. Lett. 26, 2773-2776.

Kalma, J. D., McVicar, T. R., McCabe, M. F., 2008. Estimating land surface evaporation: a review of methods using remotely sensed surface temperature data. Surv. Geophys. 29 (4-5), 421-469, doi:10.1007/s10712-008-9037$\mathrm{Z}$.

Kerr, Y. H., Waldteufel, P., Wigneron, J.-P., Delwart, S., Cabot, F., 
Boutin, J., Escorihuela, M. J., Font, J., Reul, N., Gruhier, C., Juglea, S. E., Drinkwater, M. R., Hahne, A., Martin-Neira, M., Mecklenburg, S., 2010. The SMOS mission: new tool for monitoring key elements of the global water cycle. In: IEEE. Vol. 98. pp. 666-687, doi:10.1109/JPROC.2010.2043032.

Kondratyev, K. Y., Korzov, V. I., Mukhenberg, V. V., Dyachenko, L. N., 1982. The shortwave albedo and the surface emissivity. P. S. Eagleson, Cambridge Univ. Press, UK.

Krapez, J.-C., Olioso, A., 2011. A combination of temperature, vegetation indexes and albedo, as obtained by airborne hyperspectral remote sensing, for the evaluation of soil moisture. Quant. Infr. Thermog. J. 8, 187-200, doi:10.3166/qirt.8.187-200.

Kustas, W. P., Anderson, M. C., 2009. Advances in thermal infrared remote sensing for land surface modeling. Agr. Forest Meteor. 149, 2071-2081, doi:10.1016/j.agrformet.2009.05.016.

Kustas, W. P., Daughtry, C. S. T., 1989. Estimation of the soil heat flux/net radiation ratio from spectral data. Agr. For. Meteor. 49, 205-223.

Long, D., Singh, V. P., 2012. A two-source trapezoid model for evapotranspiration (TTME) from satellite imagery. Remote Sens. Environ. 121, 370388.

Long, D., Singh, V. P., Li, Z.-L., 2011. How sensitive is SEBAL to changes in input variables, domain sizes and satellite sensor? J. Geophys. Res. 116 (D21107). 
Long, D., Singh, V. P., Scalon, B. R., 2012. Deriving theoretical boundaries to address scale dependencies of triangle models for evapotranspiration estimation. J. Geophys. Res. 117 (D05113).

Matthias, A. D., Fimbres, A., Sano, E. E., Post, D. F., Accioly, L., Batchily, A. K., Ferreira, L. G., 2000. Surface roughness effects on soil albedo. Soil Sci. Am. J. 64, 1035-1041.

Menenti, M., Bastiaanssen, W., van Eick, D., Abd el Karim, M. A., 1989. Linear relationships between surface reflectance and temperature and their application to map actual evaporation of groundwater. Adv. Space Res. 9 (1), 165-176.

Merlin, O., 2013. An original interpretation of the surface temperature-albedo space to estimate crop evapotranspiration (SEB-1S). Hydrol. Earth Syst. Sci.Submitted.

Merlin, O., Al Bitar, A., Rivalland, V., Béziat, P., Ceschia, E., Dedieu, G., 2011. An analytical model of evaporation efficiency for unsaturated soil surfaces with an arbitrary thickness. J. Appl. Meteor. Clim. 50 (2), 457471, doi:10.1175/2010JAMC2418.1.

Merlin, O., Chehbouni, G., 2004. Different approaches in estimating heat flux using dual angle observations of radiative surface temperature. Int. J. Remote Sens. 25 (1), 275-289.

Merlin, O., Duchemin, B., Hagolle, O., Jacob, F., Coudert, B., Chehbouni, G., Dedieu, G., Garatuza, J., Kerr, Y., 2010. Disaggregation of MODIS Surface Temperature over an Agricultural Area Using a Time Series 
of Formosat-2 Images. Remote Sens. Environ. 114 (11), 2500-2512, doi:10.1016/j.rse.2010.05.025.

Merlin, O., Escorihuela, M. J., Mayoral, M. A., Hagolle, O., Al Bitar, A., Kerr, Y., 2013. Self-calibrated evaporation-based disaggregation of SMOS soil moisture: an evaluation study at $3 \mathrm{~km}$ and $100 \mathrm{~m}$ resolution in Catalunya, Spain. Remote Sens. Environ. 130, 25-38, doi:10.1016/j.rse.2012.11.008.

Merlin, O., Jacob, F., Wigneron, J.-P., Walker, J., Chehbouni, G., 2012a. Multi-dimensional disaggregation of land surface temperature using high-resolution red, near-infrared, shortwave-infrared and microwaveL bands. IEEE Trans. Geosci. Remote Sens. 50 (5), 1864-1880, doi:10.1109/TGRS.2011.2169802.

Merlin, O., Rüdiger, C., Al Bitar, A., Richaume, P., Walker, J., Kerr, Y., 2012b. Disaggregation of SMOS soil moisture in southeastern Australia. IEEE Trans. Geosci. Remote Sens. 50 (5), 1556-1571, doi:10.1109/TGRS.2011.2175000.

Monteith, J. L., 1973. Principles of environmental physics. Edward Arnold Press.

Moran, M. S., Clarke, T. R., Inoue, Y., Vidal, A., 1994. Estimating crop water deficit using the relation between surface-air temperature and spectral vegetation index. Remote Sens. Environ. 49, 246-263.

Nagler, P. L., Inoue, Y., Glenn, E. P., Russ, A. L., Daughtry, C. S. T., 2003. 
Cellulose absorption index (CAI) to quantify mixed soil-plant litter scenes. Remote Sens. of Environ. 87, 310-325.

Norman, J. M., Kustas, W. P., Humes, K. S., 1995. A two-source approach for estimating soil and vegetation energy fluxes in observations of directional radiometric surface temperature. Agr. For. Meteorol. 77, 263-293.

Ogawa, K., Schmugge, T., 2004. Mapping surface broadband emissivity of the Sahara desert using ASTER and MODIS data. Earth Interactions 8 (7), $1-14$.

Oki, T., Kanae, S., 2006. Global hydrological cycles and world water resources. Science 313, 1068-1072.

Piggin, I., Schwerdtfeger, P., 1973. Variations in the albedo of wheat and barley crops. Arch. Met. Geoph. Biokl., Ser. B 21, 365-391.

Prihodko, L., Goward, S. N., 1997. Estimation of air temperature from remotely sensed surface observations. Remote Sens. Environ. 60, 335-346.

Roerink, G. J., Su, Z., Menenti, M., 2000. S-SEBI: a simple remote sensing algorithm to estimate the surface energy balance. Phys. Chem. Earth 25 (2), 147-157.

Schmugge, T. J., Hook, S. J., Coll, C., 1998. Recovering surface temperature and emissivity from thermal infrared multispectral data. Remote Sens. Environ. 65, 121-131.

Seneviratne, S. I., Luthi, D., Litschi, M., Schar, C., 2006. Land-atmosphere coupling and climate change in Europe. Nature 443, 205-209. 
Sheffield, J., Wood, E. F., 2008. Projected changes in drought occurrence under future global warming from multi-model, multi-scenario, IPCC AR4 simulations. Climate Dyn. 31, 79-105.

Su, Z., 2002. The Surface Energy Balance System (SEBS) for estimation of turbulent heat fluxes. Hydrol. Earth Syst. Sci. 6 (1), 85-99.

Tang, R., Li, Z.-L., Tang, B., 2010. An application of the Ts-VI method with enhanced edges determination for evapotranspiration estimation from MODIS data in arid and semi-arid regions: Implementation and validation. Remote Sens. Environ. 114, 540-551, doi:10.1016/j.rse.2009.10.012.

Tanguy, M., Baille, A., González-Real, M. M., Lloyd, C., Cappelaere, B., Kergoat, L., Cohard, J.-M., 2012. A new parameterisation scheme of ground heat flux for land surface flux retrieval from remote sensing information. J. Hydrol. 454-455, 113-122, doi:10.1016/j.jhydrol.2012.06.002.

Ten Berge, H., 1986. Heat and wave transfer at the bare soil surface. Aspects affecting thermal imagery. PhD Thesis, Wagenigen Univ., The Netherlands.

Timmermans, W. J., Kustas, W. P., Anderson, M. C., French, A. N., 2007. An intercomparison of the Surface Energy Balance Algorithm for Land (SEBAL) and the Two-Source Energy Balance (TSEB) modeling schemes. Remote Sens. Environ. 108, 369-384, doi:10.1016/j.rse.2006.11.028.

Wallace, J. S., 2000. Increasing agricultural water use efficiency to meet future food production. Agr. Ecosyst. Environ. 82, 105-119. 
1021 Weiss, M., Baret, F., Leroy, M., Begué, A., Hautecoeur, O., Santer, R., 1999. 1022 Hemispherical reflectance and albedo estimates from the accumulation of 1023 across track sun synchroneous satellite data. J. Geophys. Res. 104, 221$1024 \quad 232$. 
Table 1: Flux stations and instrumentation.

\begin{tabular}{cccccc} 
Station & Crop & $R n$ & $H$ & $L E$ & $G$ \\
\hline 1 & Safflower & CNR1 & Young & KH2O & HFP-01 \\
2 & Chili Pepper & Q7 & CSAT3 & KH2O & HFP-01 \\
3 & Chickpea & Q7 & CSAT3 & KH2O & HFP-01 \\
4 & Potatoes - Sorghum & Q7 & Young & KH2O & HFP-01 \\
5 & Wheat & CNR1 & CSAT3 & KH2O & HFP-01 \\
6 & Wheat & Q7 & CSAT3 & KH2O & HFP-01 \\
\hline
\end{tabular}


Table 2: Definition of component fractions. Note that $f_{v g u}$ and $f_{v g n}$ are numerical (instead of analogical) representations of the water stress of green vegetation, which can be estimated as $f_{v g n} / f_{v g}$. For instance, a field crop undergoing a water stress of 0.5 within a given pixel would be represented by $50 \%$ of fully unstressed green vegetation $\left(T_{v g}=\mathbf{T}_{\mathbf{v}, \mathbf{m i n}}\right)$ and $50 \%$ of non-transpiring vegetation $\left(T_{v g}=\mathbf{T}_{\mathbf{v}, \max }\right)$.

Component fraction Surface component

Component temperature

\begin{tabular}{ccc}
$f_{s}$ & bare soil $\left(=1-f_{v}\right)$ & $T_{s}$ \\
$f_{v g}$ & total green vegetation $\left(=f_{v g u}+f_{v g n}\right)$ & $T_{v g}$ \\
$f_{v g u}$ & unstressed green vegetation & $\mathbf{T}_{\mathbf{v}, \text { min }}$ \\
$f_{v g n}$ & non-transpiring green vegetation & $\mathbf{T}_{\mathbf{v}, \text { max }}$ \\
$f_{v s s}$ & standing senescent vegetation & $\mathbf{T}_{\mathbf{v}, \text { max }}$ \\
$f_{v}$ & total vegetation $\left(=f_{v g}+f_{v s s}\right)$ & $T_{v}$ \\
\hline
\end{tabular}


Table 3: Correlation coefficient (R), root mean square difference (RMSD), bias and slope of the linear regression between simulated and observed $R n$ and $G$ fluxes.

\begin{tabular}{|c|c|c|c|c|c|c|}
\hline Flux & $\begin{array}{c}R n \\
\text { source }\end{array}$ & $\begin{array}{c}G / R n \\
\text { formulation }\end{array}$ & $\begin{array}{l}\mathrm{R} \\
(-)\end{array}$ & $\begin{array}{l}\text { RMSD } \\
\mathrm{Wm}^{-2}\end{array}$ & $\begin{array}{c}\text { Bias } \\
\mathrm{Wm}^{-2}\end{array}$ & $\begin{array}{c}\text { Slope } \\
(-)\end{array}$ \\
\hline$R n$ & SEB-4S & NA & 0.88 & 40 & -3 & 0.87 \\
\hline$G$ & Station & $\Gamma$ & 0.59 & 50 & 4 & 0.49 \\
\hline$G$ & Station & $\Gamma^{\prime}$ & 0.67 & 44 & 1 & 0.42 \\
\hline$G$ & SEB-4S & $\Gamma$ & 0.51 & 54 & 2 & 0.40 \\
\hline$G$ & SEB-4S & $\Gamma^{\prime}$ & 0.59 & 48 & -1 & 0.34 \\
\hline
\end{tabular}


Table 4: Correlation coefficient (R), root mean square difference (RMSD), bias and slope of the linear regression between simulated and observed $L E$ fluxes for the $T-\alpha$ imagebased model, the $T-f_{v g}$ image-based model and SEB-4S and for observed and simulated available energy.

\begin{tabular}{cccccc} 
& $R n \& G$ & $\mathrm{R}$ & $\mathrm{RMSD}$ & Bias & Slope \\
Model & source & $(-)$ & $\mathrm{Wm}^{-2}$ & $\mathrm{Wm}^{-2}$ & $(-)$ \\
\hline$T-\alpha$ & Station & 0.82 & 100 & -17 & 0.63 \\
$T-f_{v g}$ & Station & 0.78 & 110 & 12 & 0.56 \\
SEB-4S & Station & 0.92 & 75 & -27 & 0.92 \\
$T-\alpha$ & SEB-4S & 0.81 & 103 & -16 & 0.63 \\
$T-f_{v g}$ & SEB-4S & 0.78 & 110 & 12 & 0.55 \\
SEB-4S & SEB-4S & 0.89 & 85 & -24 & 0.90 \\
\hline
\end{tabular}




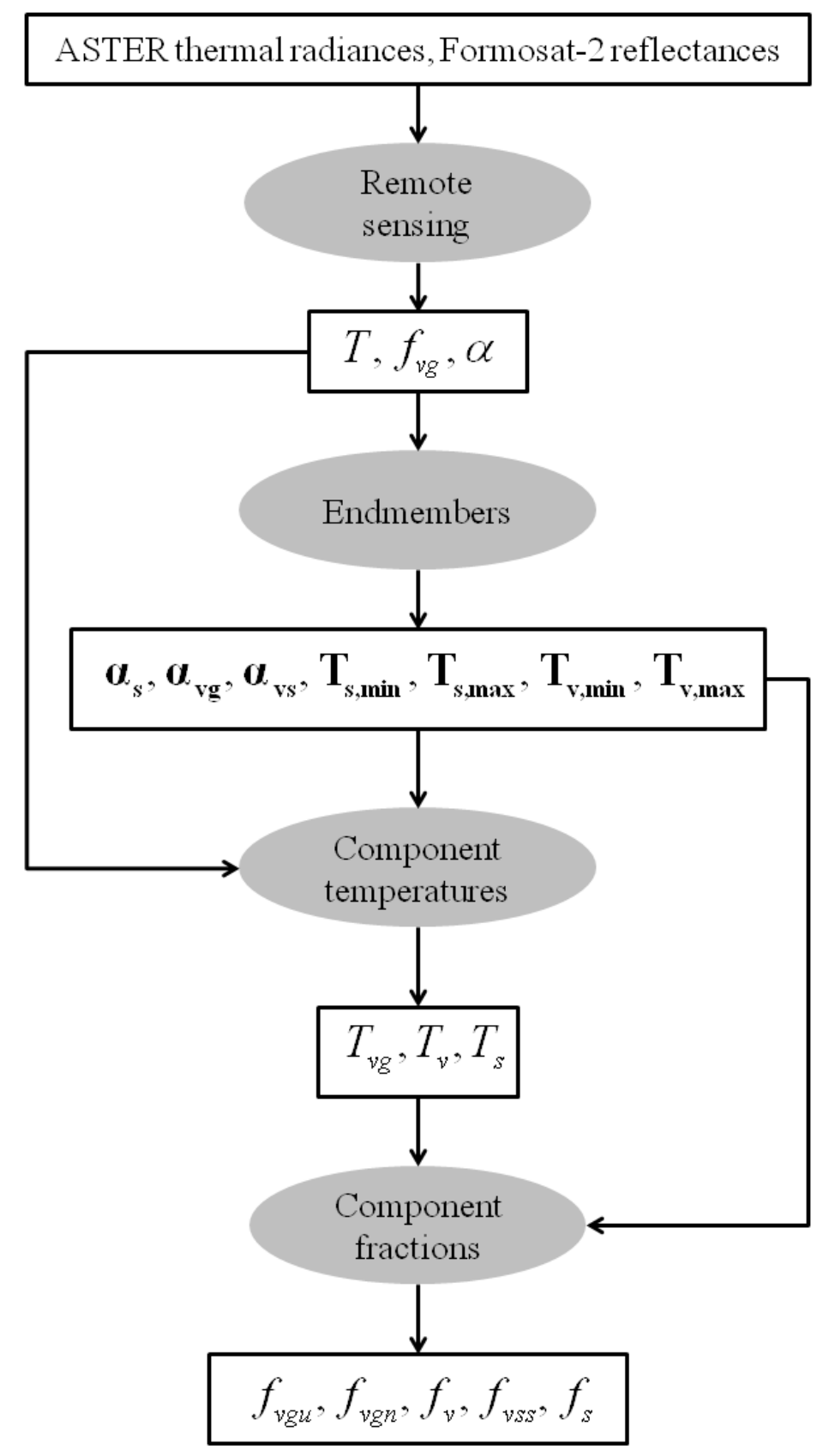

Figure 1: Data processing steps for determination of component fractions. 


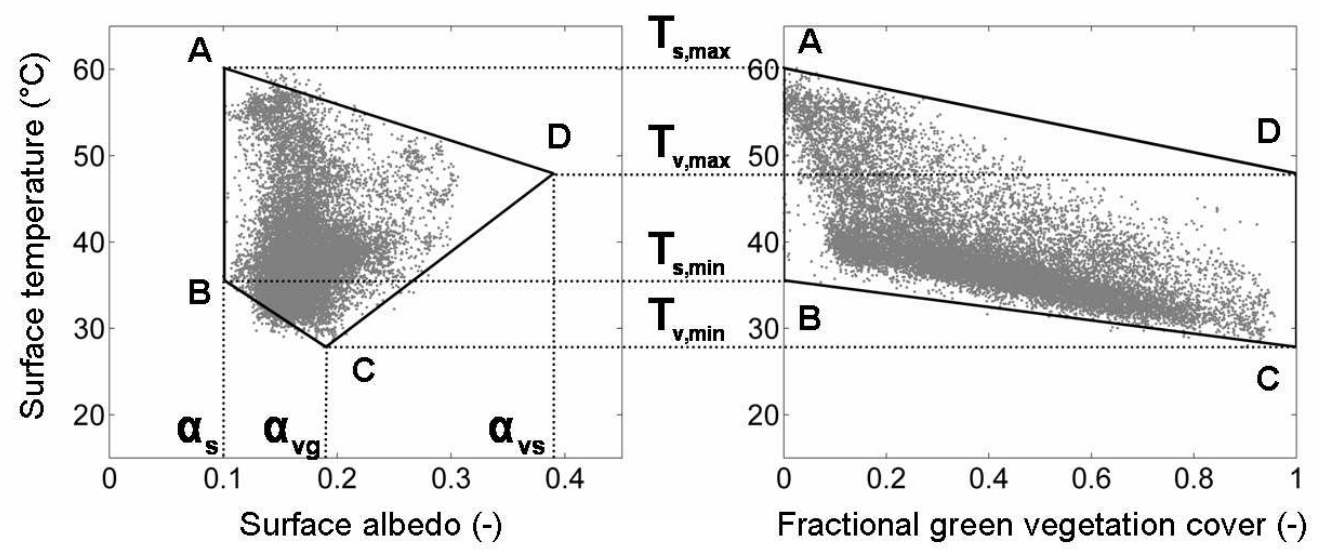

Figure 2: Consistent interpretation of the edges and vertices of the $T-\alpha$ and $T-f_{v g}$ polygons. Underlying grey points correspond to $T$, $\alpha$, and $f_{v g}$ data on 27 April 2008. 


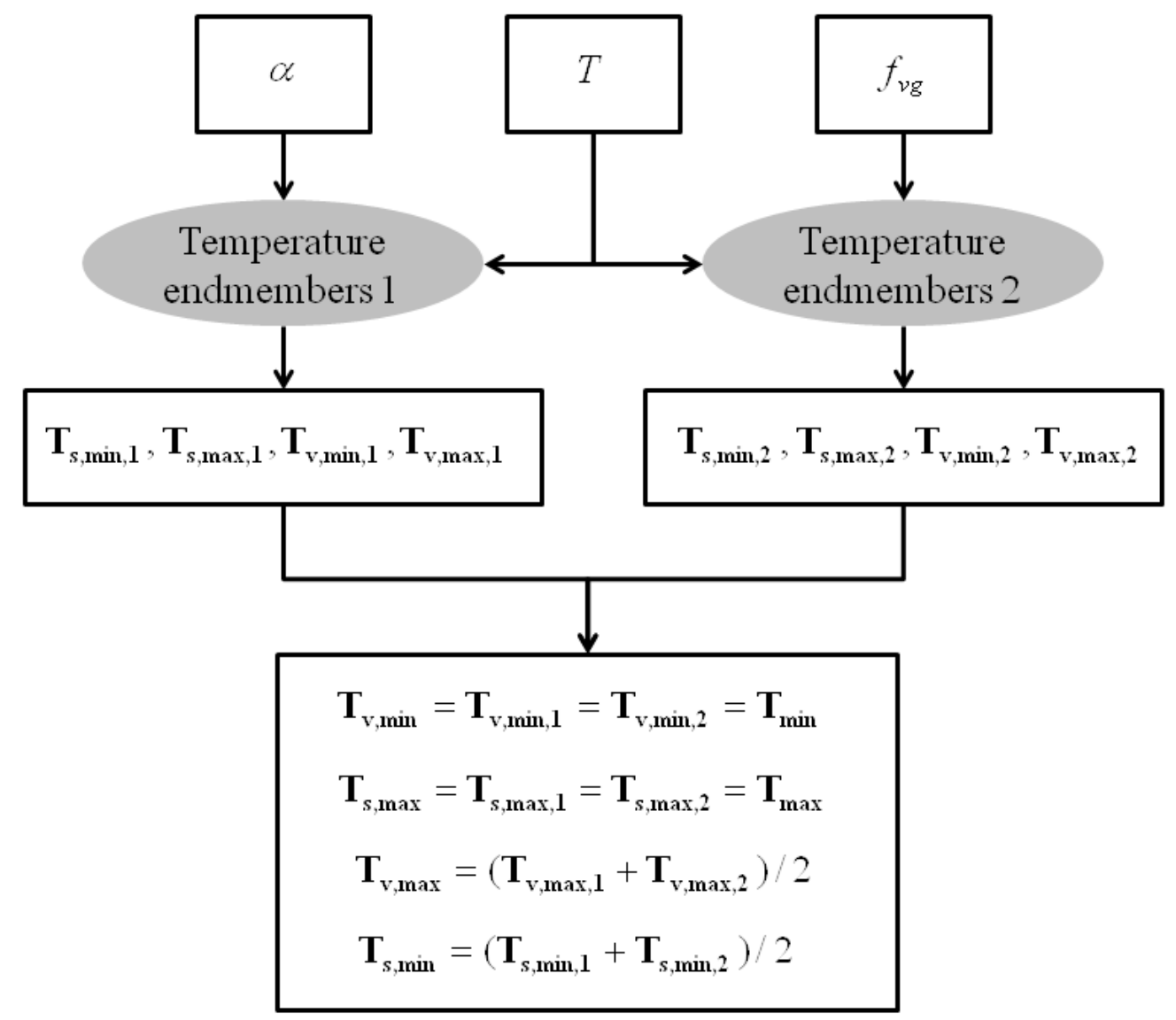

Figure 3: Data processing steps for determination of temperature endmembers. 

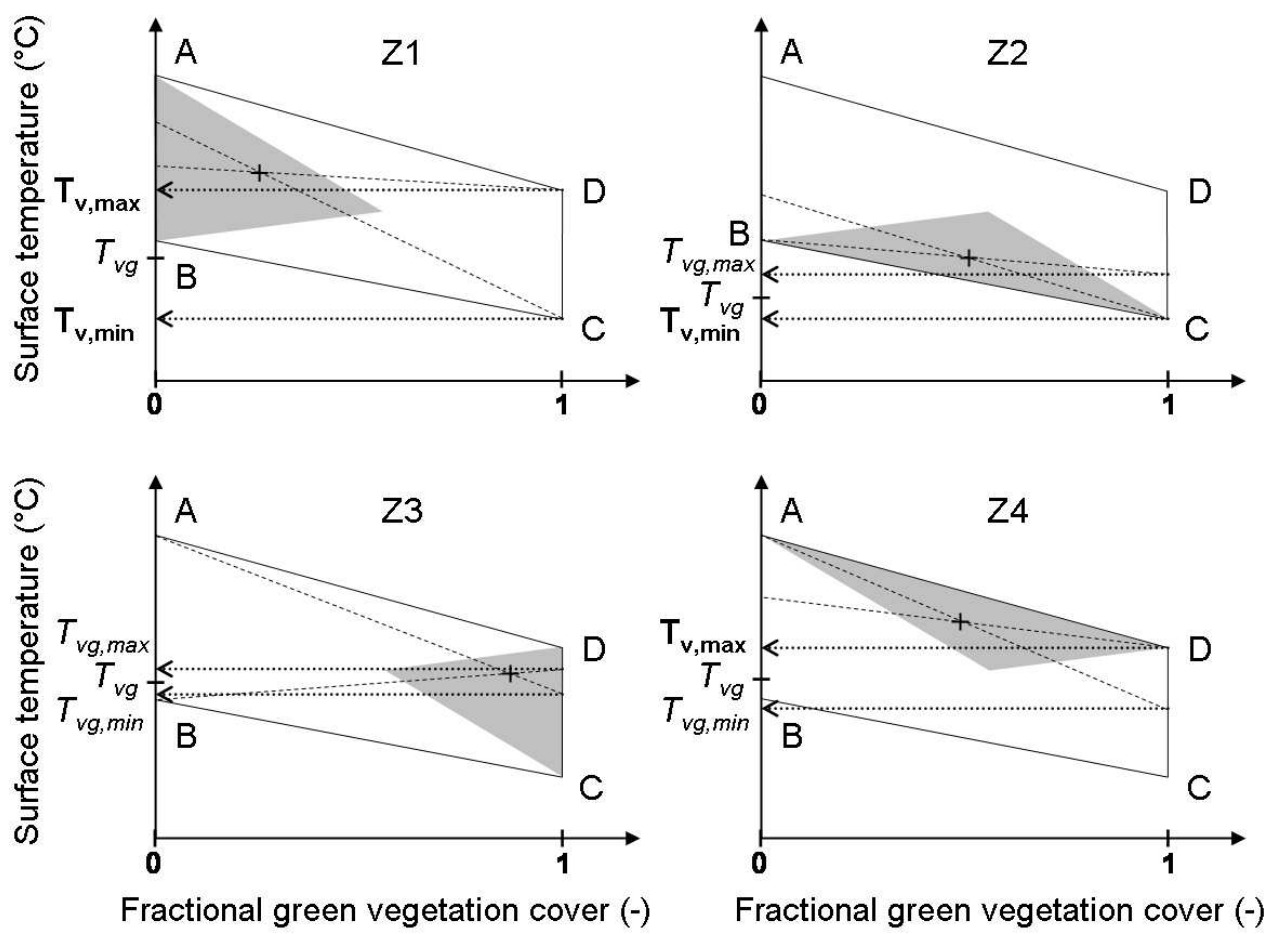

Figure 4: Most probable $T_{v g}$ is estimated by applying the hourglass approach to the $T-f_{v g}$ polygon. 

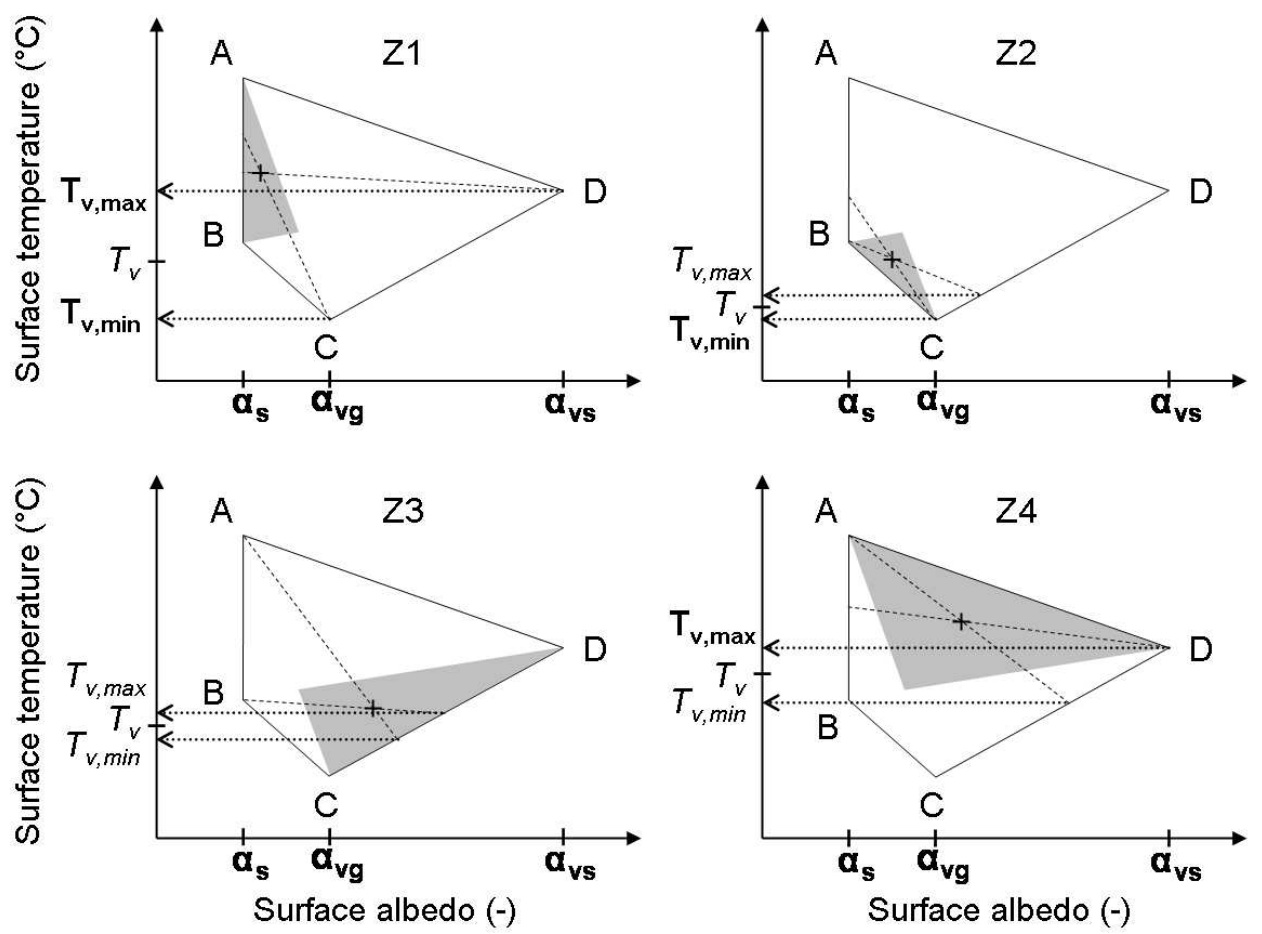

Figure 5: Most probable $T_{v}$ is estimated by applying the hourglass approach to the $T-\alpha$ polygon. 


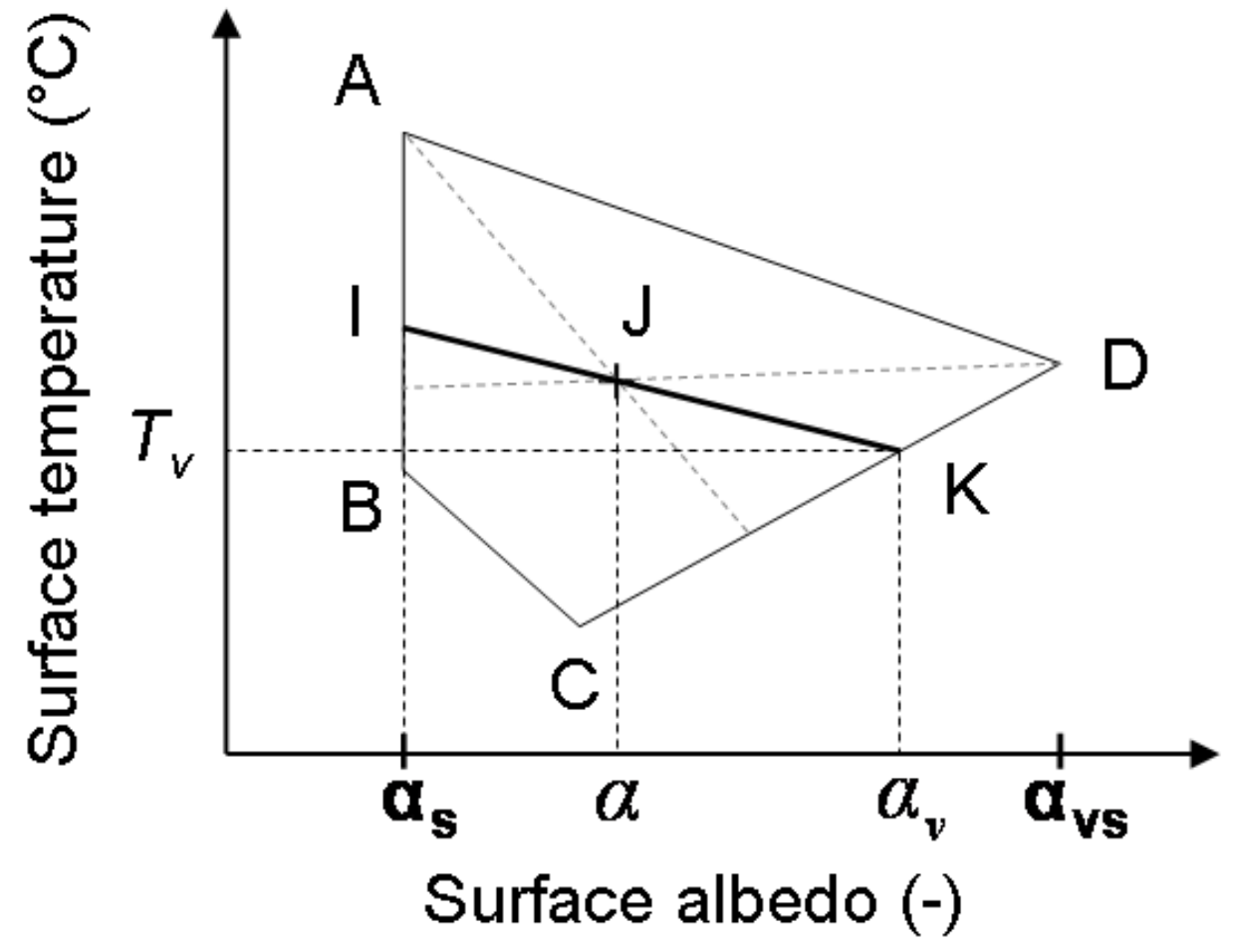

Figure 6: $f_{v}$ is estimated as the ratio IJ/IK $=\left(\alpha-\alpha_{\mathbf{s}}\right) /\left(\alpha_{v}-\alpha_{\mathbf{s}}\right)$. 

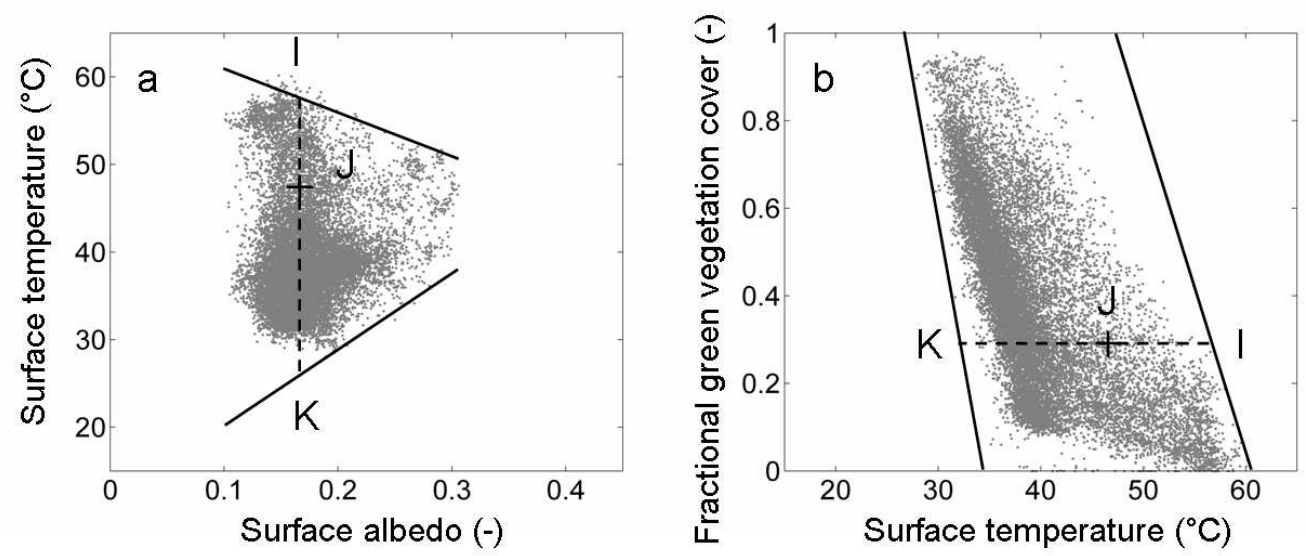

Figure 7: EF is computed as IJ/IK in the $T-\alpha$ image-based (a) and the $T-f_{v g}$ imagebased (b) model. 


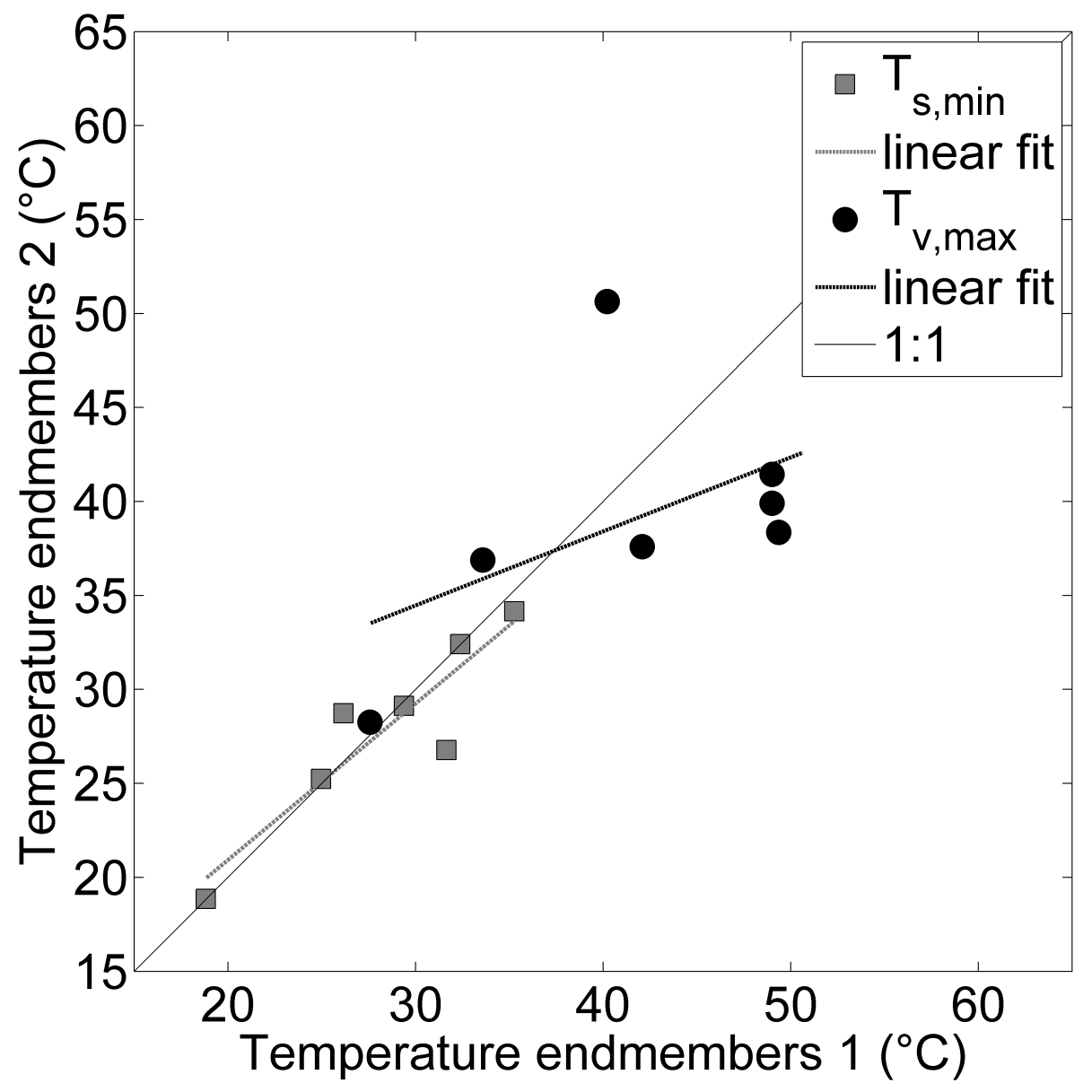

Figure 8: Temperature endmembers set 1 (derived from the $T-\alpha$ space) and set 2 (derived from the $T-f_{v g}$ space) are intercompared in terms of $\mathbf{T}_{\mathbf{s}, \text { min }}$ and $\mathbf{T}_{\mathbf{v}, \text { max }}$. 

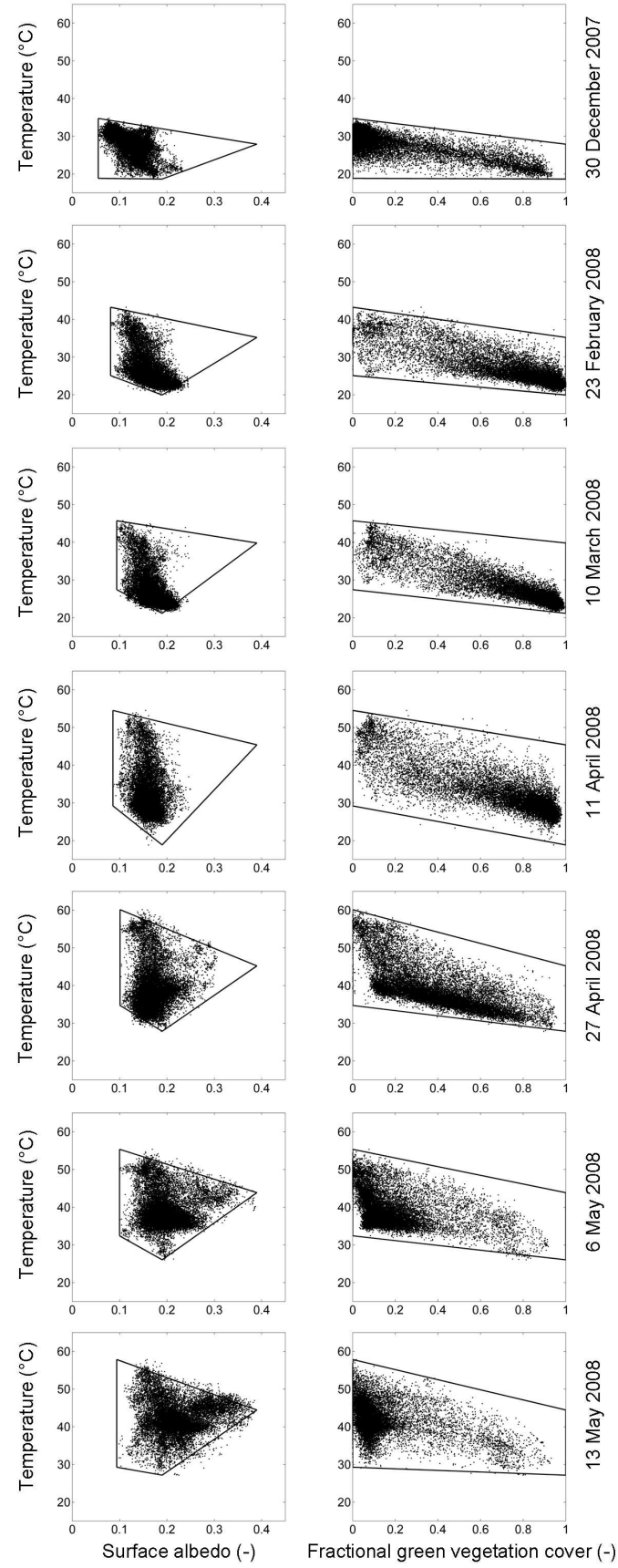

Figure 9: Estimating temperature endmembers by a consistent interpretation of the $T-\alpha$ and $T-f_{v g}$ spaces. 

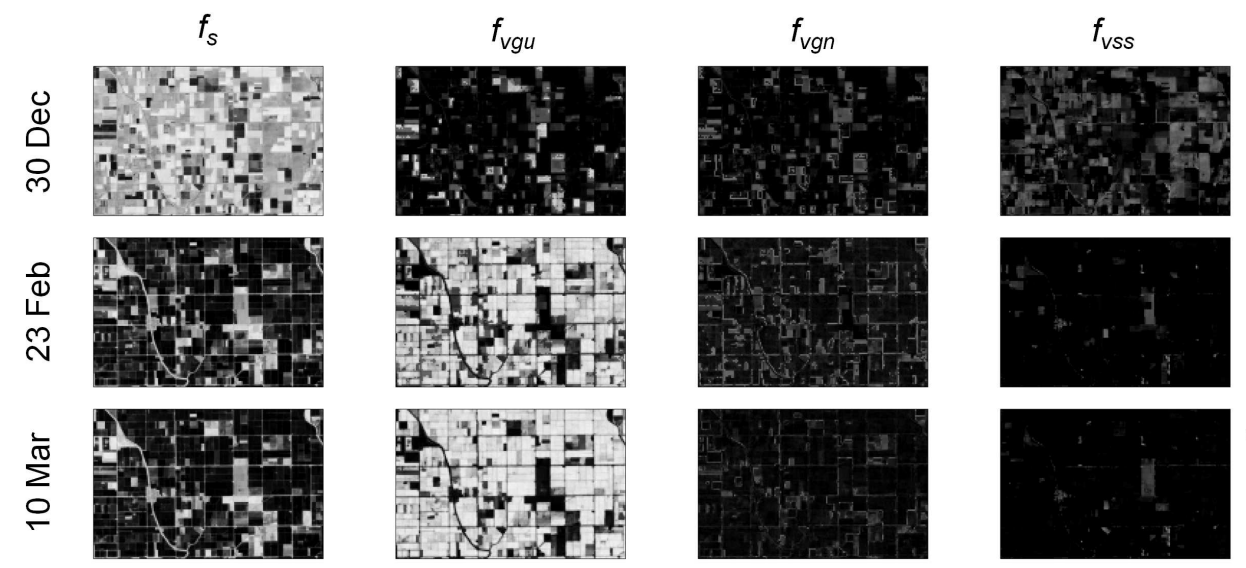

$1(-)$
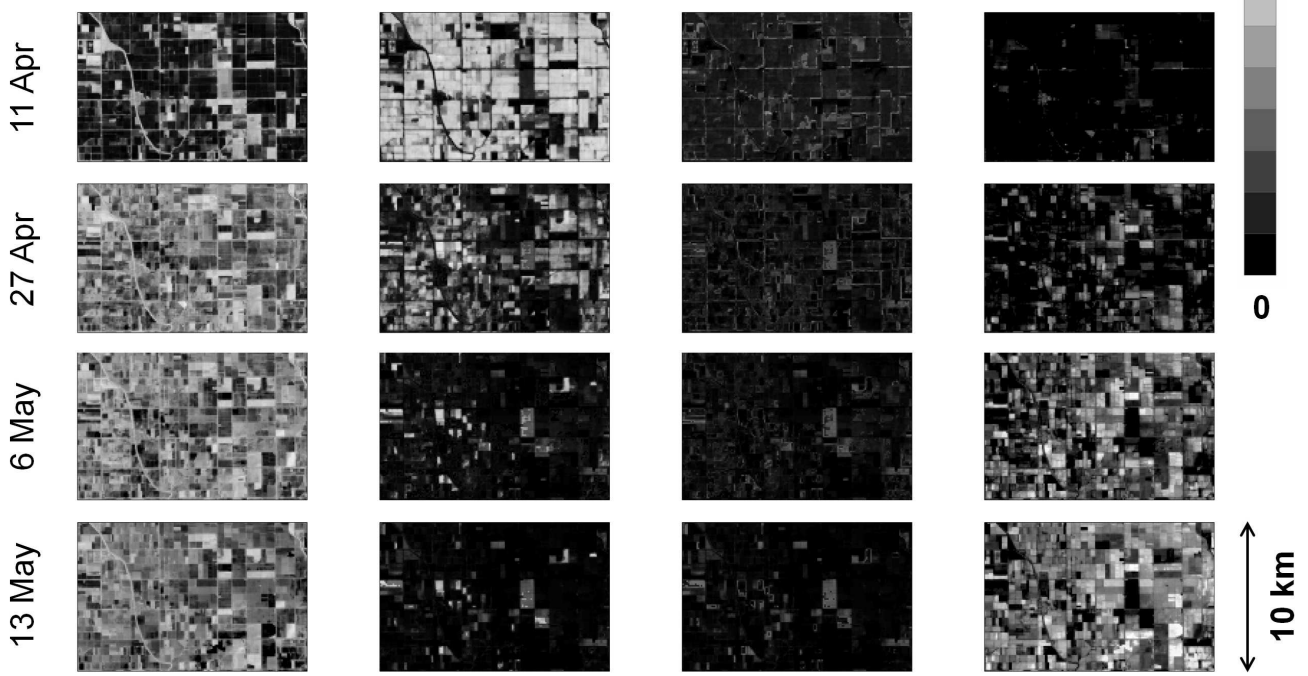

Figure 10: Component fractions on the seven ASTER overpass dates. 


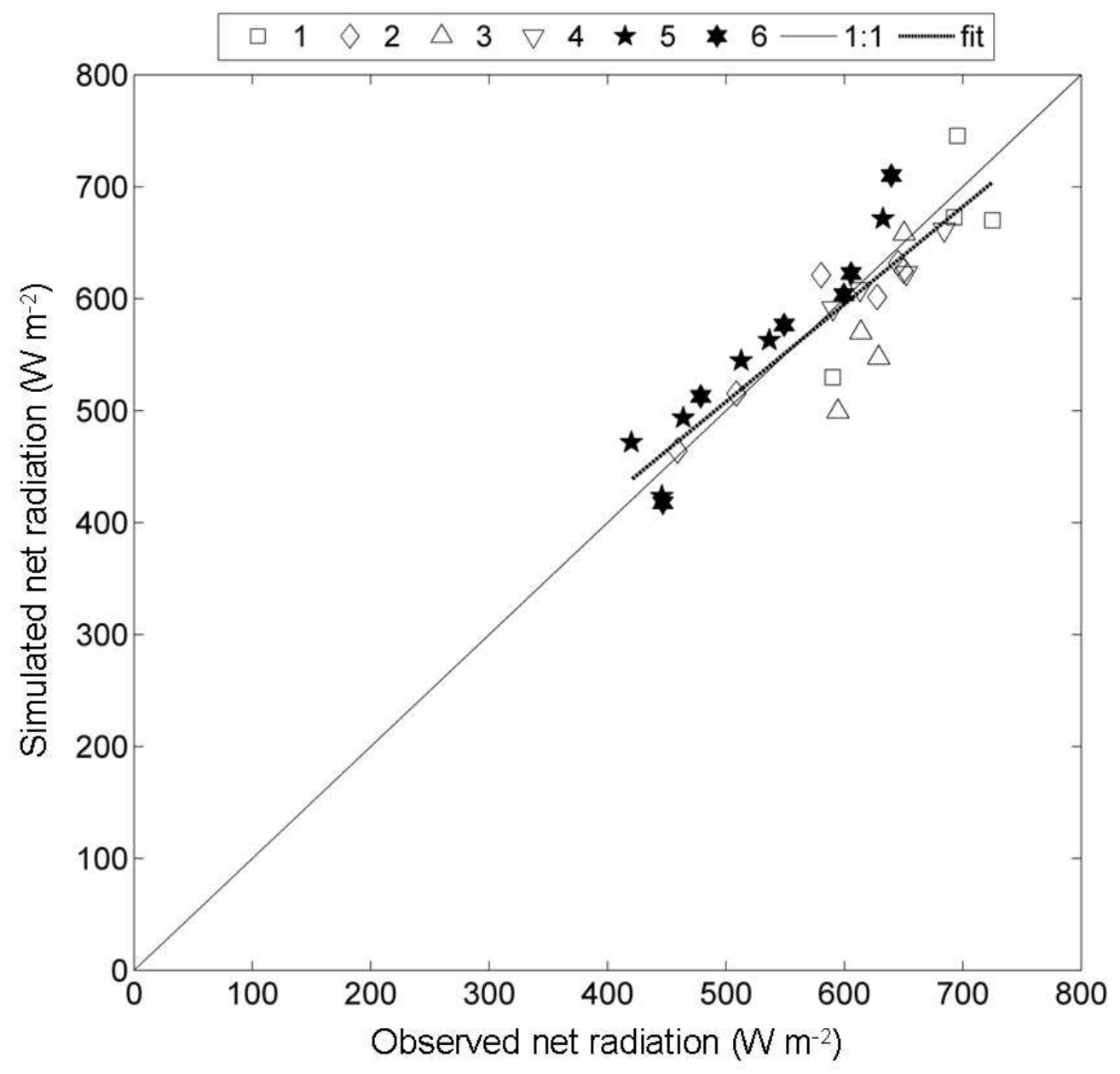

Figure 11: Modeled versus observed net radiation. 

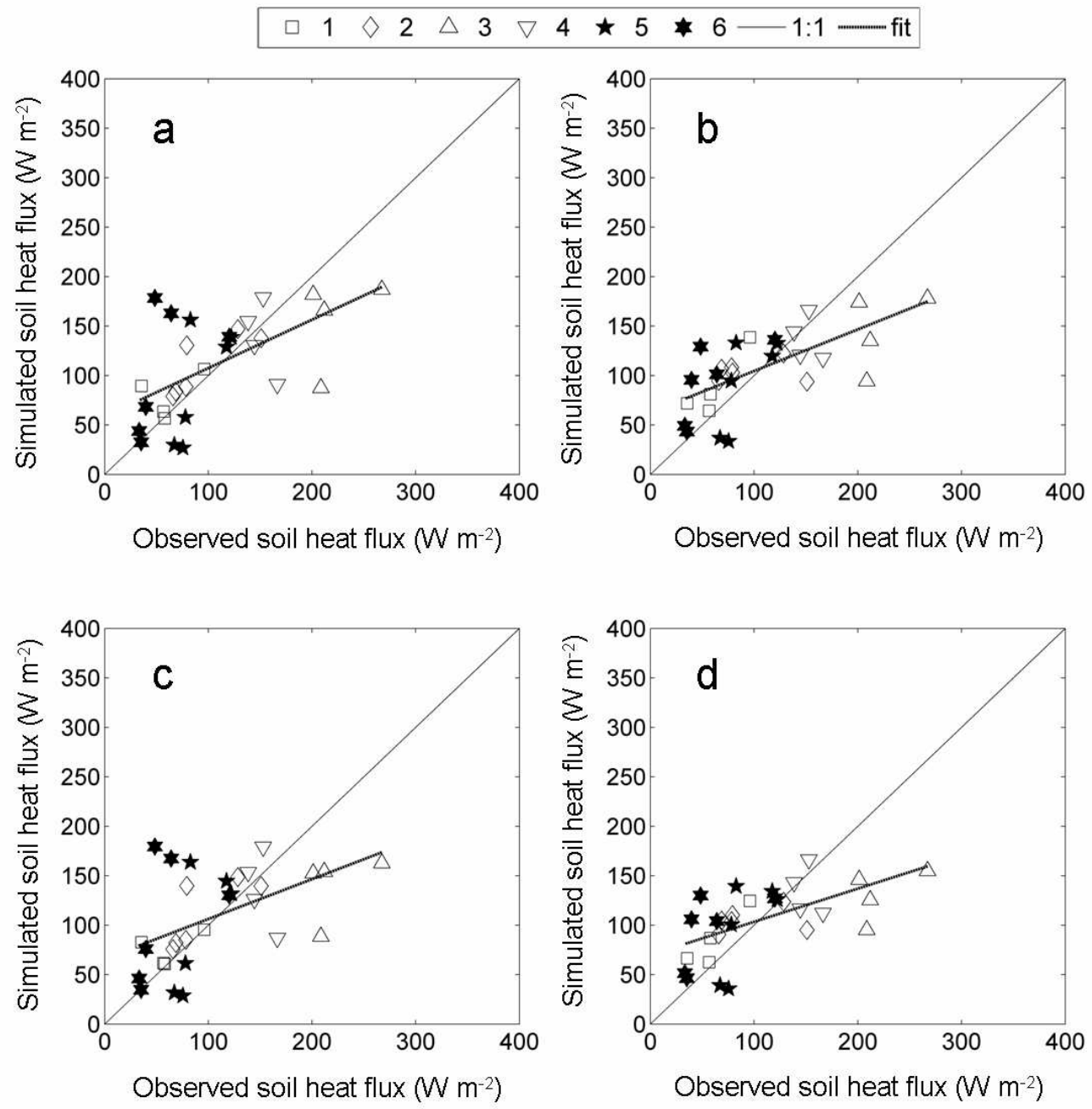

Figure 12: The ground heat flux simulated using $\Gamma$ and observed $R n$ (a), $\Gamma^{\prime}$ and observed $R n$ (b), $\Gamma$ and simulated $R n$ (c), and $\Gamma^{\prime}$ and simulated $R n(\mathrm{~d})$ are plotted versus station measurements. 

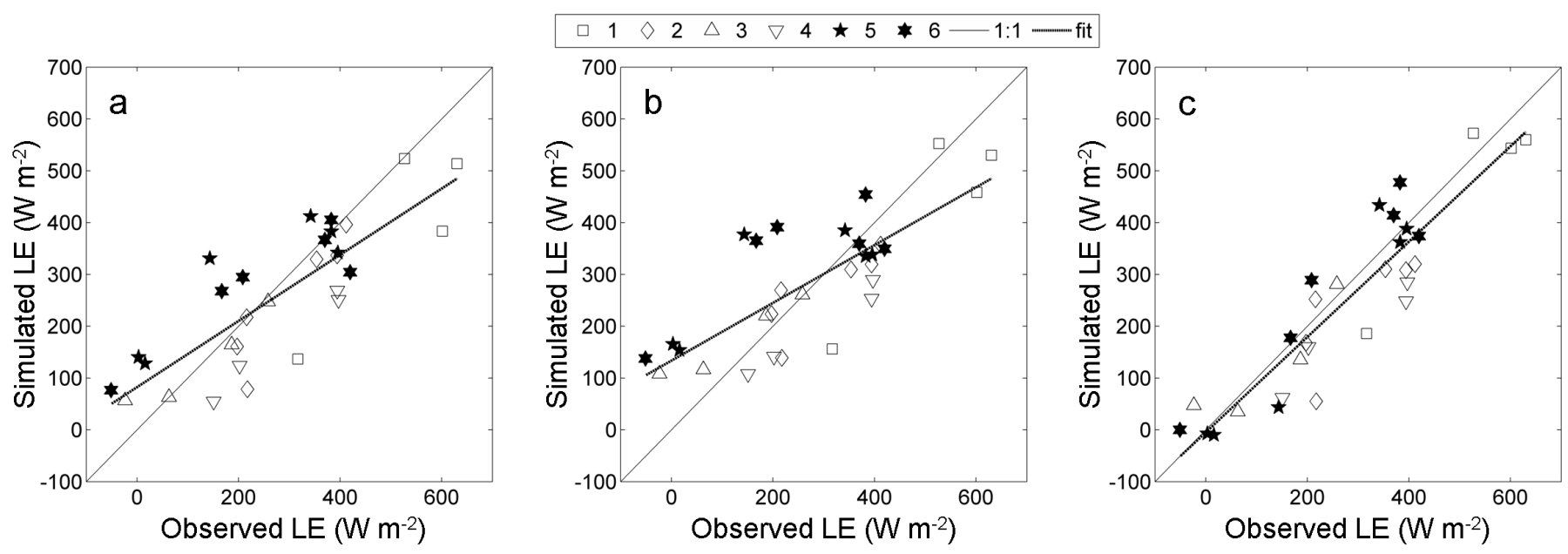

$\stackrel{9}{9}$
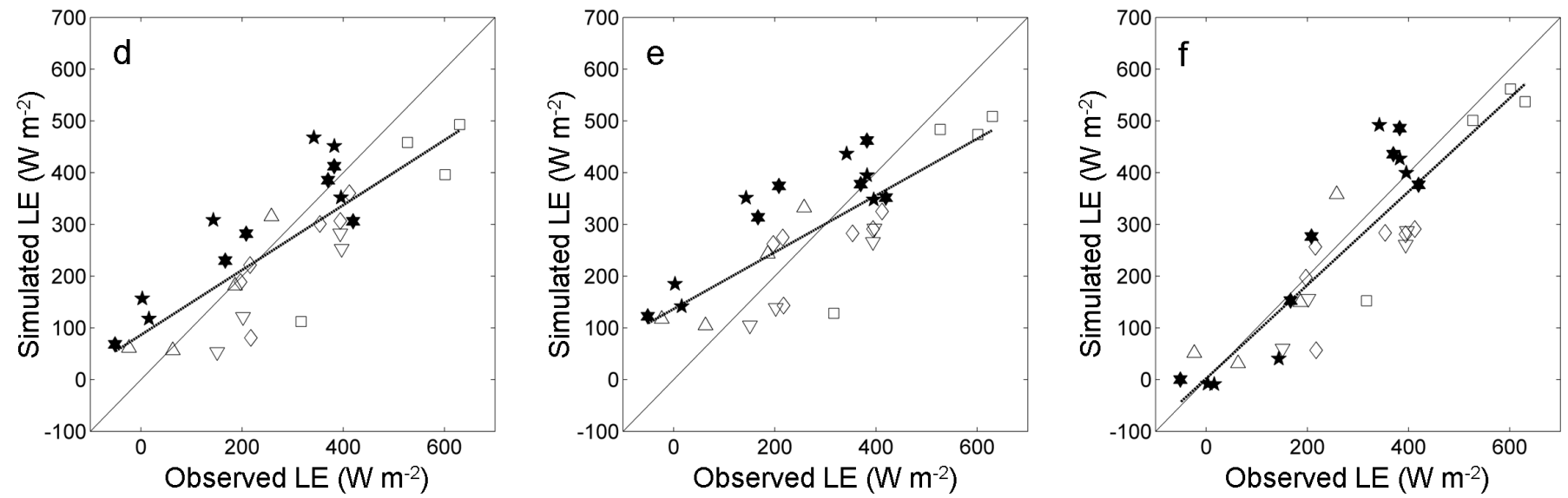

Figure 13: The ET simulated by the $T-\alpha$ image-based model (left), the $T-f_{v g}$ image-based model (middle), and SEB- $4 \mathrm{~S}$ (right) is plotted versus station measurements. The top line corresponds to data simulated using observed available energy $(R n-G)$, and the bottom line corresponds to data simulated using modeled available energy. 

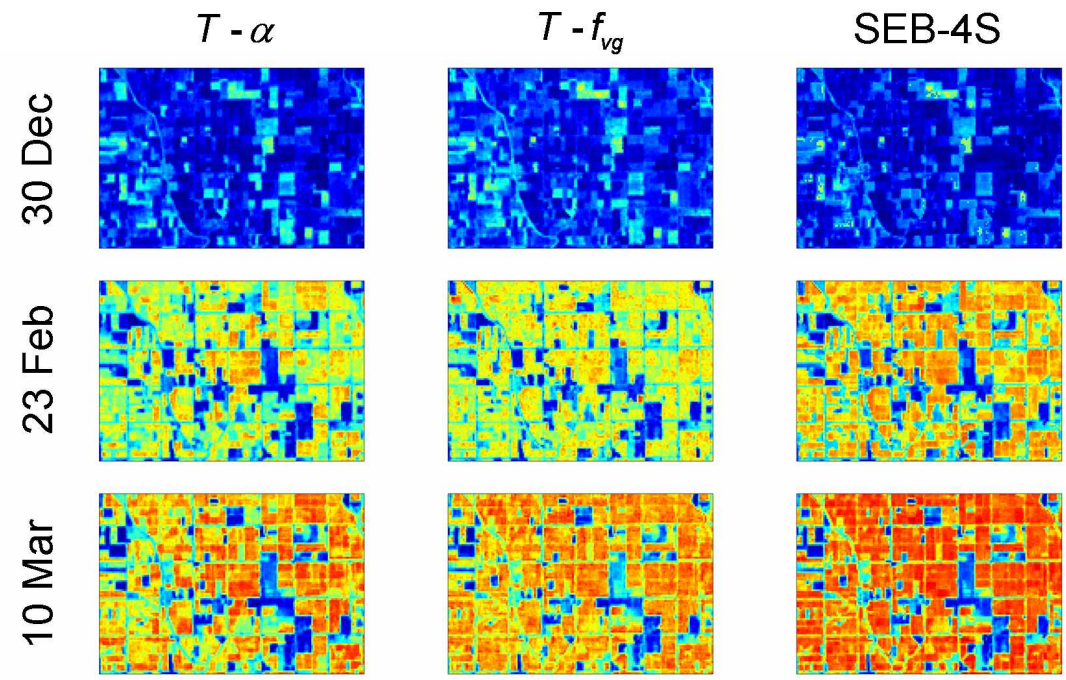

\section{$L E\left(\mathrm{~W} \mathrm{~m}^{-2}\right)$}
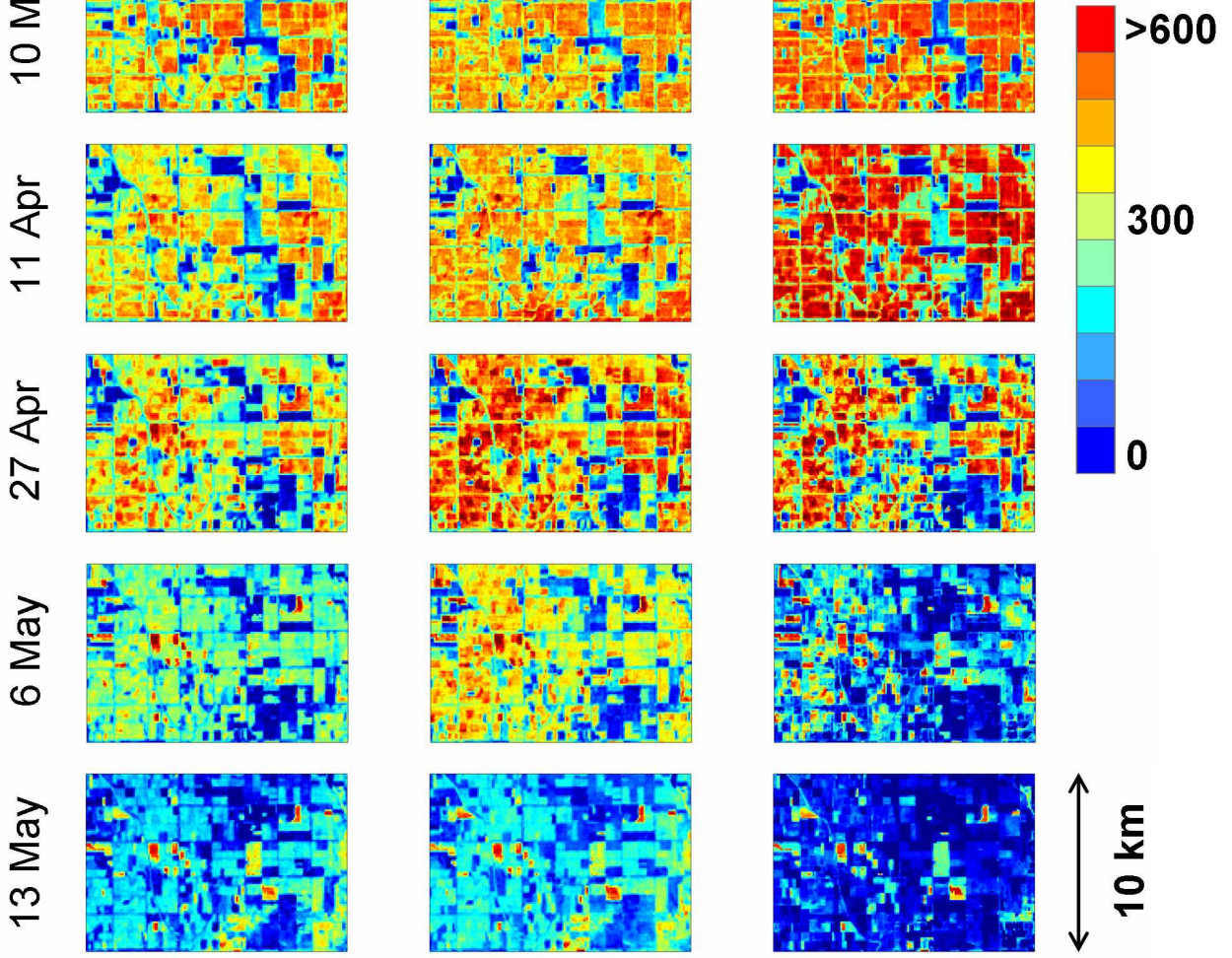

Figure 14: ET images simulated on the seven ASTER overpass dates by the $T-\alpha$ imagebased model, the $T-f_{v g}$ image-based model, and SEB-4S. 